\title{
G Protein-Coupled Receptors in Taste Physiology and Pharmacology
}

\author{
Raise Ahmad* and Julie E. Dalziel \\ Food Nutrition and Health Team, Food and Bio-based Products Group, AgResearch, Palmerston North, New Zealand
}

Heterotrimeric G protein-coupled receptors (GPCRs) comprise the largest receptor family in mammals and are responsible for the regulation of most physiological functions. Besides mediating the sensory modalities of olfaction and vision, GPCRs also transduce signals for three basic taste qualities of sweet, umami (savory taste), and bitter, as well as the flavor sensation kokumi. Taste GPCRs reside in specialised taste receptor cells (TRCs) within taste buds. Type I taste GPCRs (TAS1R) form heterodimeric complexes that function as sweet (TAS1R2/TAS1R3) or umami (TAS1R1/TAS1R3) taste receptors, whereas Type II are monomeric bitter taste receptors or kokumi/calcium-sensing receptors. Sweet, umami and kokumi receptors share structural similarities in containing multiple agonist binding sites with pronounced selectivity while most bitter receptors contain a single binding site that is broadly tuned to a diverse array of bitter ligands in a non-selective manner. Tastant binding to the receptor activates downstream secondary messenger pathways leading to

OPEN ACCESS

Edited by:

Michelle L. Halls,

Monash University, Australia

Reviewed by:

Walter Glen Thomas, The University of Queensland,

Australia

Katie Leach,

Monash University, Australia

${ }^{*}$ Correspondence:

raise.ahmad@agresearch.co.nz

Specialty section:

This article was submitted to Experimental Pharmacology and Drug

Discovery,

a section of the journal

Frontiers in Pharmacology

Received: 27 July 2020 Accepted: 09 October 2020

Published: 30 November 2020

Citation:

Ahmad R and Dalziel JE (2020) G Protein-Coupled Receptors in Taste

Physiology and Pharmacology.

Front. Pharmacol. 11:587664.

doi: 10.3389/fphar.2020.587664 depolarization and increased intracellular calcium in TRCs, that in turn innervate the gustatory cortex in the brain. Despite recent advances in our understanding of the relationship between agonist binding and the conformational changes required for receptor activation, several major challenges and questions remain in taste GPCR biology that are discussed in the present review. In recent years, intensive integrative approaches combining heterologous expression, mutagenesis and homology modeling have together provided insight regarding agonist binding site locations and molecular mechanisms of orthosteric and allosteric modulation. In addition, studies based on transgenic mice, utilizing either global or conditional knock out strategies have provided insights to taste receptor signal transduction mechanisms and their roles in physiology. However, the need for more functional studies in a physiological context is apparent and would be enhanced by a crystallized structure of taste receptors for a more complete picture of their pharmacological mechanisms.

Keywords: taste receptor, taste bud, flavor, taste ligand, signal transduction, gustducin, peptide

\section{INTRODUCTION}

G protein-coupled receptors (GPCRs) are the largest and the most diverse group of membrane receptors in eukaryotes. They are activated by a wide variety of ligands in the form of light energy, lipids, sugars, peptides and proteins (Billington and Penn, 2003; Schoneberg et al., 2004; Lundstrom, 2009) which convey information from the outside environment into the cell to mediate their corresponding functional responses. The conformational changes of GPCRs upon ligand binding initiate a series of biochemical reactions within the cell. These intracellular reactions regulate sensory functions of smell, taste, and vision, and a wide variety of physiological processes such as secretion, 


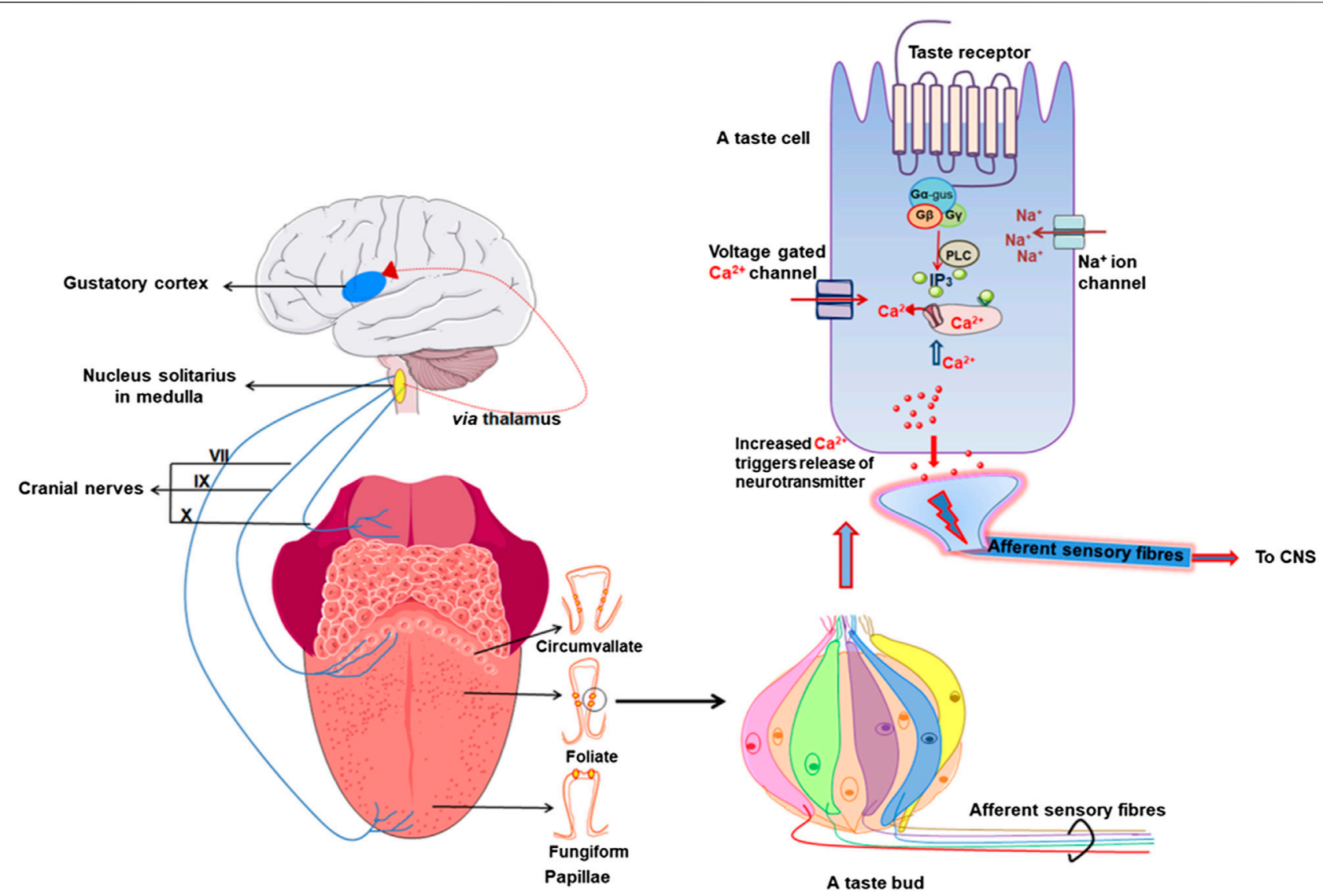

FIGURE 1 | Schematic diagram shows taste signal transmission between tongue and brain. Taste buds present in different papillae in tongue and palate contain taste receptor cells (TRC) which contain taste G protein-coupled receptors (GPCRs). Left side shows how afferent nerves transmit a signal to the gustatory cortex in brain via cranial/glossopharyngeal nerves. Right side shows taste bud with taste TRCs and simplified signal transduction pathway of taste receptor where taste GPCRs are activated by a tastant that in turn recruits a specific G protein that further induces intracellular calcium release (created with BioRender.com).

neurotransmission, metabolism, cellular differentiation, inflammation and immune responses (Lagerström and Schiöth, 2008; Rosenbaum et al., 2009; Venkatakrishnan et al., 2013; Ahmad et al., 2015). Taste is one of the most important sensations for human life, enabling us to perceive different tastes from the diverse range of food available in nature and is a major determinant of our ingestion decisions.

The anatomical units of taste detection are taste receptor cells (TRCs) that are assembled into taste buds distributed across different papillae of the tongue and palate epithelium. Taste processing is first achieved at the level of TRCs that are activated by specific tastants. They transmit information via sensory afferent fibers to the gustatory cortex in the brain for taste perception (Figure 1). Three different morphologic subtypes of TRCs in taste buds sense the different tastes we perceive. Type I glial-like cells detect salty taste while type II cells expressing GPCRs detect sweet, umami, and bitter tastes. Type III cells sense sour stimuli (Janssen and Depoortere, 2013).

Sweet and umami stimuli are transduced by Type 1 taste GPCRs while bitter taste is sensed by Type 2 taste GPCRs (Figure 2; Table 1). The more recently described kokumi sensation is mediated by another GPCR, the calcium-sensing receptor (CaSR) (Figure 2; Table 1). Taste GPCRs are activated by specific taste ligands present in foods and recruit $G$ proteins to activate downstream signaling effectors (Figure 3 ).

In this review, we will first explore the basic architecture of the gustatory sensory system and its peripheral signal transmission. Then we will discuss taste GPCR signal transduction mechanisms for the different taste modalities, their molecular structure, and the conformational changes that occur following orthosteric/ allosteric binding of endogenous and food-derived ligands.

\section{TASTE BUDS AND NEURAL TRANSMISSION}

In mammals, taste buds on the tongue comprise 50-100 elongated epithelial cells and a small number of proliferative basal cells (Sullivan et al., 2010). Ultrastructural studies and patterns of gene expression with cell function reveal three distinct anatomical types of TRCs within each taste bud: Type I, Type II and Type III (Murray, 1986) (refer to Figure 2; Table 2). 


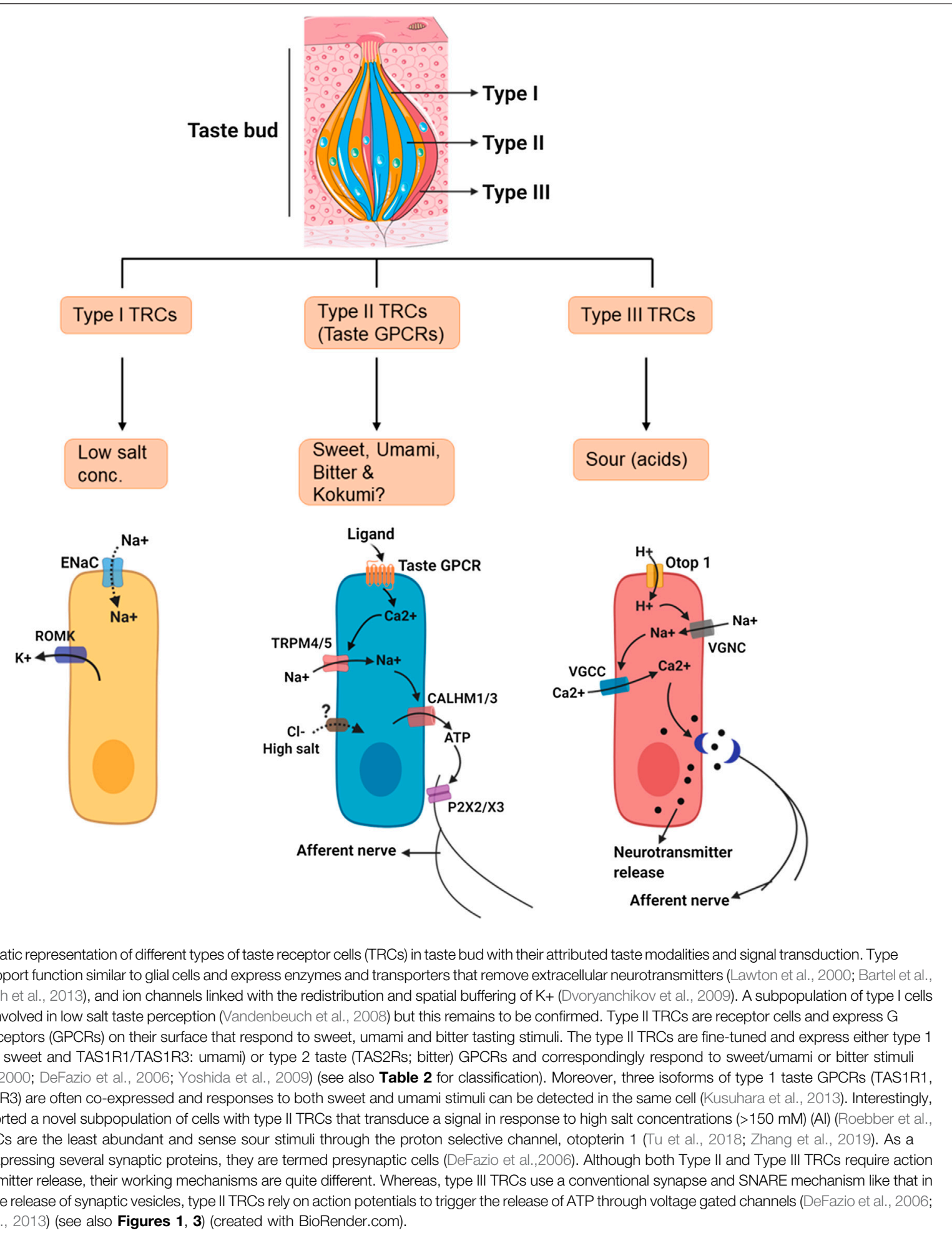

Type II TRCs express either sweet, umami, or bitter taste receptors at their cell surface. These receptors share some commonality to their signal transduction mechanisms that are intrinsic to TRCs. Taste GPCRs (sweet, umami and bitter) couple to heterotrimeric $\mathrm{G}$ proteins that include $\mathrm{G} \alpha$-gustducin, $\mathrm{G} \beta 3$, and
G $\gamma 13$ (Huang et al., 1999) and initiate a series of signal transduction cascades involving activation of phospholipase C- $\beta 2$ (PLCB2), production of inositol-1,4,5-triophosphate (IP3), and IP3-dependent $\mathrm{Ca}^{2+}$ release from the endoplasmic reticulum (ER) via the IP3 receptor (IP3R). The increased 
TABLE 1 | Taste GPCRs classification and their downstream signaling regulators.

\begin{tabular}{|c|c|c|c|c|}
\hline $\begin{array}{l}\text { Taste/flavor } \\
\text { sensation }\end{array}$ & Sweet & Umami & Bitter & Kokumi \\
\hline GPCRs & TAS1R2 + TAS1R3 & TAS1R1 + TAS1R3 & TAS2Rs & Calcium sensing receptor \\
\hline Class of GPCR & Class C & Class C & Class A & Class C \\
\hline Type & Type 1 taste GPCRs & Type 1 taste GPCRs & Type 2 taste GPCRs & ND \\
\hline Oligomerization & Heterodimer & Heterodimer & Monomer & Homodimer \\
\hline Ga Subunit & Ga-gustducin & Ga-gustducin & Ga-gustducin & Gq/11, Gi/o, G12/13, Gs \\
\hline Signaling pathway & $\begin{array}{l}\text { G } \beta \gamma \text {-PLC } \beta 2 \text {-TRPM5 pathway- } \\
\text { semaphorin } 7 A\end{array}$ & G $\beta \gamma$-PLC $\beta 2-T R P M 5$ pathway & $\begin{array}{l}\text { G } \beta \gamma \text {-PLC } \beta 2-\text { TRPM5 pathway- } \\
\text { semaphorin 3A }\end{array}$ & G $\beta \gamma$-PLC $\beta 2$-TRPM5 pathway \\
\hline Ligand binding sites & VFT; TMD & VFT, TMD & ND & VFT, TMD \\
\hline Potent ligands & $\begin{array}{l}\text { Sucrose, aspartame, } \\
\text { sucralose, cyclamate }\end{array}$ & L-amino acids, Gultamate & Peptides, alkaloids, flavonoids & $\begin{array}{l}\mathrm{Ca}^{2+} \text {, divalent and trivalent cations, } \\
\text { Glutathione, } \gamma \text {-glutamyl peptides, } \\
\text { polyamines, amino acids }\end{array}$ \\
\hline Antagonists/NAMs & Lactisole, gymnemic acid & Lactisole, clofibric acid & GIV3727, probenecid & NPS2143 \\
\hline Food source & Sugar/sweets, dairy products & $\begin{array}{l}\text { Savoury food, fermented dairy/meat/ } \\
\text { fish/chicken broth, mushroom, tomato }\end{array}$ & $\begin{array}{l}\text { Wine, tea, coffee, cheese, } \\
\text { broccoli }\end{array}$ & $\begin{array}{l}\text { Garlic/onion meat/fish/broth/ } \\
\text { mushroom, soy sauce }\end{array}$ \\
\hline
\end{tabular}

TAS2R, bitter taste receptors; GPCR, G protein-coupled receptors; VFT, extracellular Venus flytrap domain; TMD, seven transmembrane domain; ND, not defined.

intracellular $\left[\mathrm{Ca}^{2+}\right]_{\mathrm{i}}$ then activates the transient receptor potential cation channel subfamily $\mathrm{M}$ member 4 and 5 (TRPM4/5) in the basolateral plasma membrane, leading to membrane depolarization that triggers $\mathrm{Na}^{+}$action potential firing, and depolarization-induced release of ATP. In turn, ATP acts as the primary neurotransmitter stimulating purinergic receptors 2 and 3 ( $\mathrm{P} 2 \mathrm{X} 2$ and $\mathrm{P} 2 \mathrm{X} 3$ ) on afferent cranial nerves whose activation triggers an action potential which subsequently activates the gustatory cortex in the brain (McLaughlin et al., 1992; Wong et al., 1996; Margolskee, 2002). a-gustducin is a distinct $G$ protein selectively expressed in $\sim 30 \%$ of type II TRCs and shares $80 \%$ identity with retinal protein $\alpha$-transducin (McLaughlin et al., 1992) and is a key contributor to signal transduction for sweet and bitter taste receptors (McLaughlin et al., 1992; Wong et al., 1996; Margolskee, 2002).

An important aspect of taste transduction is how ATP signaling is conducted. Recent studies have discovered that calcium homeostasis modulators 1 and 3 (CALHM1/3) are enriched in type II TRCs where they interact and form a functional complex. Their genetic deletion abolishes responses to sweet, bitter and umami tastes, supporting the requirement of the CALHM1/3 complex as an ATP release channel for the GPCRs mediated tastes (Taruno et al., 2013; Ma et al., 2018).

New information has provided insight into how specific taste qualities are fine-tuned in order to recognize their partner ganglionic neurons in the brain. Lee et al. (2017) discovered semaphorin proteins, 7A and 3A as the physical links between sweet and bitter TRCs, respectively, and their partner ganglion neurons in the brain. It remains to be determined what physical links exist between umami TRCs and their corresponding neurons in the brain. Delineating the underlying molecular basis for this interaction would provide further understanding of purinergic transmission in the taste system. In addition, whether these mechanisms are relevant for kokumi sensation has not yet been investigated, despite CaSR having distinct expression in TRCs and significant functional synergy with other prominent taste qualities (sweet, umami and salty). Moreover, there is still debate regarding the recognition of kokumi as a sixth taste entity, consequently the calcium sensing receptor (CaSR) is not yet included in the nomenclature for any subtypes of taste GPCRs, although it would best fit with Type 1 taste receptors.

\section{Type 1 Taste G Protein-Coupled Receptors (Sweet and Umami)}

The type 1 taste receptors (TAS1Rs) belong to the class C GPCRs, which possess a large $\mathrm{N}$-terminal extracellular domain (ECD) fused to the heptahelical seven transmembrane domain (TMD). The ECD is further divided into two ligand-binding domains (LBD1 and LBD2), having a bi-lobed structure called a Venus flytrap domain (VFT) due to its resemblance to this shape (Hoon et al., 1999). With the exception of $\mathrm{GABA}_{\mathrm{B}}$ receptors, a cysteinerich domain (CRD) connects the VFT to the TMD (Leach and Gregory, 2017).

In contrast to other receptors from this class $\mathrm{C}$ of GPCRs, such as the metabotropic glutamate receptor (mGluR) or $\gamma$-aminobutyric acid type B receptors (GABABRs) which function as homo- or heterodimers, respectively (Jones et al., 1998; Kaupmann et al., 1998; White et al., 1998; Kunishima et al., 2000), the TAS1Rs function as obligatory heterodimers. The distinct expression pattern of TAS1R1 and TAS1R2 in different subsets of murine cells led to the idea that they could detect two different taste profiles. However, following the discovery of the TAS1R3 subtype, it was clear that when TAS1R1 heterodimerizes with TAS1R2, the receptor detects sweet taste substances (Nelson et al., 2001; Ohkuri et al., 2009; Kim et al., 2017). On the other hand, if heterodimerized with TAS1R3 (TAS1R1/TAS1R3), it is responsible for umami or amino acid taste detection (Li et al., 2002; Nelson et al., 2002). Please refer to figure $\mathbf{4 A}$ for the basic structure of sweet and umami receptors. 


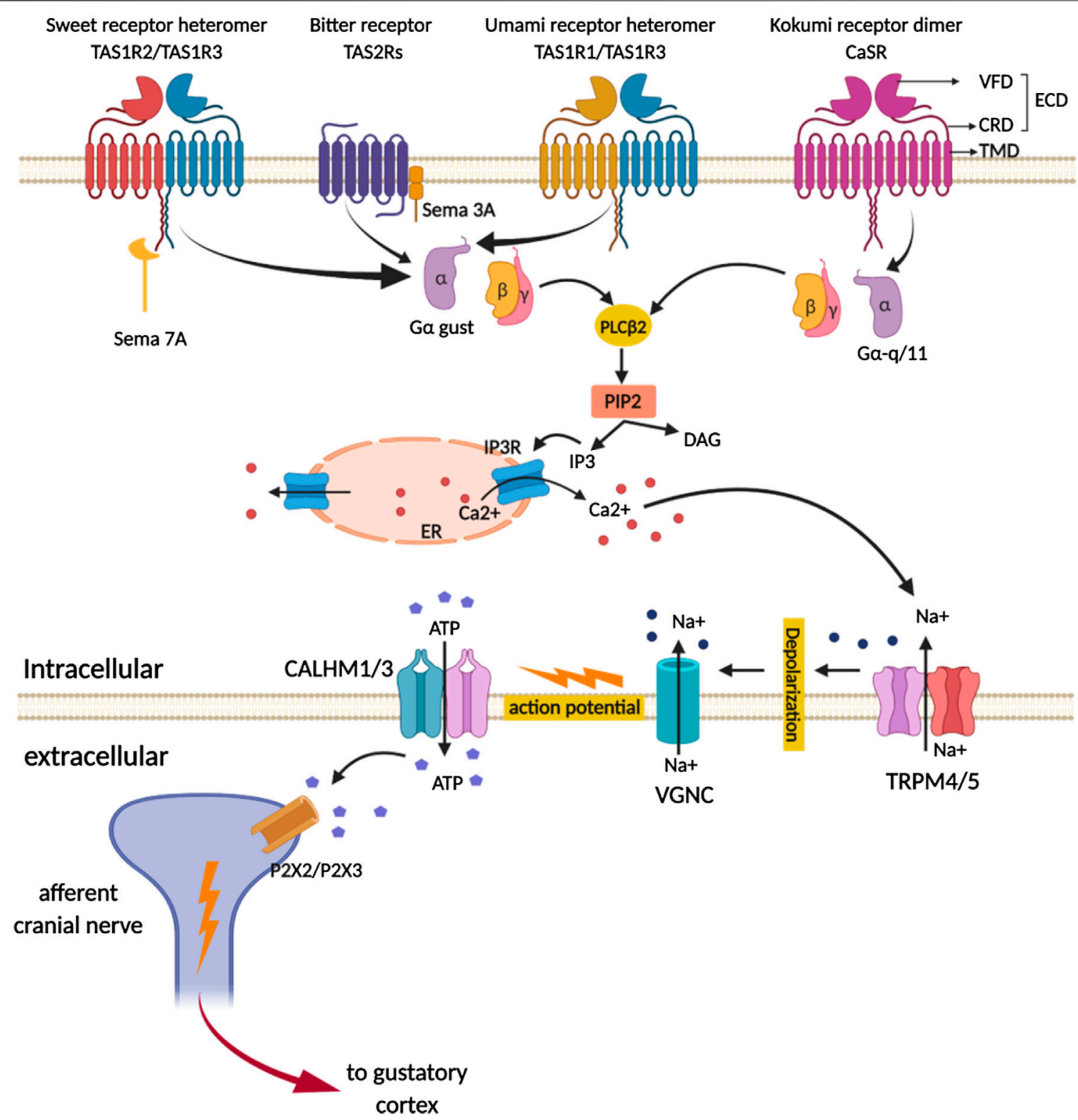

FIGURE 3 | Schematic representation of signal transduction pathway of sweet, umami, bitter and kokumi-calcium sensing receptors (CaSR) in taste receptor cells on the tongue. Ligand-induced stimulation of the sweet (TAS1R2/TAS1R3), umami (TAS1R1/TAS1R3), bitter receptors (TAS2Rs) and kokumi sensation expressed in type II taste cells within taste bud activates a trimeric $\mathrm{G}$ protein composed of $\alpha$-gustducin (Ga-gust) in sweet, umami, bitter and Ga-q/11 in kokumi-receptor and a complex consisting of $G \beta \gamma$ proteins. The released $G \beta \gamma$-complex activates phospholipase $C$ isoform $\beta 2$ (PLC $\beta 2$ ) which then induces production of inositol 1,4,5trisphosphate (IP3) and diacylglycerol (DAG); the second messenger IP3, in turn activates the IP3 receptor (IP3R), an intracellular ion channel that allows Ca ${ }^{2+}$ release from the intracellular endoplasmic reticulum (ER store). Increase in intracellular $\mathrm{Ca}^{2+}$ then activates the complex of transient receptor potential cation channel subfamily $\mathrm{M}$ member 4 and 5 (TRPM4/5) that are plasma membrane localized sodium-selective channels which leads to depolarization and subsequent activation of voltage-gated sodium channels (VGSC). The combined action of increased $\mathrm{Ca}^{2+}$ and membrane depolarization activates the complex of calcium homeostasis modulator 1 and 3(CALHM1/3) channel and pannexin1 channels, thus resulting in the release of the neurotransmitter ATP. Increased ATP, in turn activates P2X ionotropic purinergic receptors 2 and 3 (P2X2/P2X3) on afferent cranial nerve generating an action potential that subsequently signals to the gustatory cortex for sensory perception. Besides well-known taste GPCR pathways, connecting proteins semaphorin 7A (Sem 7A) and 3A (Sem 3A) are depicted in close contact with sweet and bitter receptors as they provide instructive signals that fine tune to sweet or bitter ganglion neurons, respectively. VFT, venus flytrap domain; CRD, cystine rich domain; ECD, extracellular domain. (created with BioRender.com). 
TABLE 2 | Summary of taste receptor cell characteristics.

\begin{tabular}{|c|c|c|c|}
\hline $\begin{array}{l}\text { Taste receptor } \\
\text { cells }\end{array}$ & Type I & Type II & Type III \\
\hline Cell type & $50 \%$ of the total population & $20-30 \%$ & $5-10 \%$ \\
\hline Taste responses & Low salt taste amiloride sensitive response & $\begin{array}{l}\text { Sweet, biiter, umami and probably kokumi flavor } \\
\text { response (?) via GPCRs }\end{array}$ & Sour response via otopterin 1 \\
\hline Morphology & $\begin{array}{l}\text { Spindle shaped with long brush like microvilli } \\
(1-2 \mathrm{~mm}) \text {, no synapse }\end{array}$ & Long and slender short microvilli, no synapse & $\begin{array}{l}\text { Single large microvillus, have synaptic contact } \\
\text { with afferent nerve }\end{array}$ \\
\hline Other functions & $\begin{array}{l}\text { Support function, ion redistribution, } \\
\text { neurotransmitter clearance }\end{array}$ & High salt taste amiloride insensitive response? & Probable salt response? \\
\hline Marker proteins & GLAST, $\mathrm{K}^{+}$channel (ROMK) & CALHM1, CALHM3, pannexin, connexins & Kir2.1, PDK2L1, SNAP25, synapsinll, NCAM \\
\hline
\end{tabular}

GLAST, glutamate aspartate transporter; ROMK, renal outer medullary potassium channel; PDK2L1, polycystin 2 like 1, transient receptor potential cation channel; CALHM, calcium homeostasis modulator; Kir2.1, inward rectifier K(+) channel; NCAM, neural cell adhesion molecule; SNAP25, synaptosome associated protein 25 kDa.

\section{SWEET TASTE SIGNAL TRANSDUCTION MECHANISMS}

The TAS1R2/TAS1R3 receptor recognizes a wide variety of sweet substances including natural sugars, artificial sweeteners, amino acids and proteins (Li et al., 2002; Xu et al., 2004; Jiang et al., 2005a; Jiang et al., 2005c) (Table 3). This was demonstrated in studies using heterologous expression systems as well as knockout mice for TAS1R2 and/or TAS1R3 subtypes that showed a blunted response to sugars, sweeteners, and D-amino acids, confirming the TAS1R2/TAS1R3 heterodimer as the main sweet taste receptor in vivo (Li et al., 2002; Zhao et al., 2003; Xu et al., 2004).

The sweet receptor couples to heterotrimeric $\mathrm{Ga}$-gustducin which includes $G \beta 3$ and $G \gamma 13$, as mice lacking $G a$-gustducin showed a reduced response to sweet substances either natural or artificial (McLaughlin et al., 1992; Wong et al., 1996; Margolskee, 2002). Moreover, a point mutation in the C-terminal region of gustducin (G352P) (critical for its receptor interaction) results in loss of its ability to activate taste GPCRs while keeping other functions intact. Further, G352P acts as a dominant negative to block heterotrimeric $\mathrm{G}$ protein interaction with taste receptors and disrupts the responses to sweet and bitter compounds in both wild type (WT) and null mice (Ruiz-Avila et al., 2001). In addition, the G352 mutant further reduces any residual sweet/ bitter taste responses of the null mice by acting as a " $\beta \gamma$ sink" to bind all unbound $\beta \gamma$-subunits and remove them from the viable pool of $G$ protein heterotrimers available to the receptor (RuizAvila et al., 2001). These observations confirm the essential requirement of $\mathrm{Ga}$-gustducin in sweet and bitter taste transduction.

In addition to the Ga-gustducin pathway, sweet taste transduction occurs via two additional signaling pathways involving different secondary messengers. The first one involves cAMP and the second one involves IP3. Normally, sugars elevate the level of CAMP, while sweeteners stimulate IP3 production (Tonosaki and Funakoshi, 1988; Uchida and Sato, 1997). Sucrose or other sugars bind to either TAS1R2 or TAS1R3 and recruit Gas protein that leads to increased cAMP levels which initiates the influx of cations through ion channels. Alternatively, cAMP activates protein kinase A that leads to TRC cell depolarization resulting in an influx of calcium ions and neurotransmitter release (Avenet et al., 1988; Tonosaki and
Funakoshi, 1988; Margolskee, 2002). Sweetener binding to the TAS1R2/TAS1R3 heterodimer recruits Ga-gustducin proteins that stimulate PLC $\beta 2$ which in turn hydrolyzes phosphatidylinositol 4,5-bisphosphate (PIP2) to diacylglycerol (DAG) and IP3 (Margolskee, 2002; Chandrashekar et al., 2006). IP3R3 (Hisatsune et al., 2007) induced $\mathrm{Ca}^{2+}$ release from ER stores (Figure 3) activates TRPM5 (Zhao et al., 2003; Hisatsune et al., 2007; Dutta Banik et al., 2018) that leads to an action potential (Yoshida et al., 2005; Yoshida et al., 2006) and subsequent release of neurotransmitters.

Interestingly, Dutta Banik et al. (2018) confirmed that TRPM4 also mediates taste signaling independent of TRPM5, and knocking out both channel proteins (TRPM4/5) abolishes the sweet, umami and bitter taste response completely. This revealed another layer of complexity to sweet signal transmission. This indepth mechanistic research has increased our understanding of sweet and bitter receptors and presents a challenge to dissect the taste signal transmission pathways for umami and kokumi as well.

\section{Structural, Molecular and Conformational Changes of Sweet Receptor}

Since, the sweet taste receptor has not yet been crystallized, determining the structure of the sweetener binding site and mechanism of activation has been a challenge. Based on homology with other class C GPCRs (mGluRs and GABA ${ }_{B}$ Rs), multiple studies propose similar activation mechanisms for the sweet receptor (Kunishima et al., 2000; Tsuchiya et al., 2002; Jingami et al., 2003; Muto et al., 2007; Perez-Aguilar et al., 2019). The many different sweet agonists and their diverse binding sites across receptor domains (VFT, TMD and CRD) (Table 3) may explain its complex yet broadly tuned nature. For example, a single residue in VFT (I60) of TAS1R3 of the TAS1R2/TAS1R3 heteromer is required for a saccharin preference in in-bred mouse strains (Max et al., 2001; Reed et al., 2004).

Several studies utilizing homology and computational modeling based on the crystal structure of mGluR and $\mathrm{GABA}_{\mathrm{B}} \mathrm{Rs}$ have predicted structural and functional aspects of orthosteric and allosteric binding sites for the sweet receptor (Kim et al., 2017; Cheron et al., 2019; Park et al., 2019). They reported that both VFT regions undergo ligand dependent conformational changes and intersubunit interactions between 
ECDs that further stabilize heterodimer formation for subsequent downstream signaling (Perez-Aguilar et al., 2019). Binding of orthosteric agonists to VFT of TAS1R2 leads to major conformational changes that form a TMD6/TMD6 interface between TMDs of TAS1R2 and TAS1R3, which is consistent with the activation process observed biophysically on the mGluR2 homodimer. The initial role of the bound agonist is to pull the bottom part of VFT3 (VFT of TAS1R3) toward the bottom part of VFT2 (VFT of TAS1R2) in order to transmit this movement from VFT2 (where agonists bind) through the VFT3 and the CRD3 (VFT and CRD of TAS1R3) to the TMD3 (TMD of TAS1R3). This facilitates G protein coupling and downstream signaling. The CRDs are crucial in this streamlined relay of structural changes where disulfide bonds provide rigidity to the CRD and amplify the mechanical constraints that help in attaining an active conformation (Cheron et al., 2019). This is empirically supported by a study in which a single mutation (A537P) in the CRD of TAS1R3 abolished the response to all sweeteners, indicating that the CRD3 must couple ligand binding in VFT2 to the conformational changes required in TMD3 for receptor activation.

Trafficking and cell surface expression are also crucial factors for sweet taste transduction. Molecular modeling with mutagenesis scanning revealed specific regions consisting of hydrophobic residues in ECD (site II; at the tip of CRD) and TMD regions (site IV; includes TMD6 and the cytoplasmic base of TMD5) of the TAS1R2 subunit to be important for dimerization with TAS1R3. Moreover, the CRD region and ECL2 domain of the transmembrane region seem to be important for surface co-expression of the TAS1R2/TAS1R3 dimer. In particular, the cytosolic C-terminus portion of the CRD region of TAS1R2 needs to be properly folded for coexpression and trafficking (Park et al., 2019). This reflects the difficulty in expressing these receptors at consistent levels in mammalian cell lines (Li et al., 2002; Shimizu et al., 2014).

\section{Positive Allosteric Modulation of Sweet Receptor}

Class C GPCRs pose an ideal target for allosteric modulation either positive (PAM) or negative (NAM). PAMs show little or no agonist activity on their own but significantly enhance agonist activity. Sweet taste is a major target of the food industry globally and non-caloric sweeteners are highly sought to exploit a huge commercial market. In a first comprehensive high throughput screen by Servant et al. (2010), novel PAMs (SE1, SE2, SE3; Table 4) for the sweet heteromer were reported that were not sweet on their own but significantly enhanced the sweetness of sucralose or sucrose. Agonist binding to the VFT region of TAS1R2, facilitates a closed conformation which constitutes an active state of the sweet receptor, while its open conformation represents an inactive state. Molecular modeling and mutagenesis studies revealed that these PAMs follow a similar mode of binding as that reported for umami PAMs (IMP and GMP). They bind near the opening of the binding pocket of the VFT region adjacent to their agonists, through Van der Waals and hydrogen bonding interactions, and utilize several critical residues for their activity. Although these residues are not in direct contact with any receptor bound sweetener, mutation of some of them (K65, Y103, L279, D307, and R383) diminishes the response to sweeteners suggesting that these residues normally stabilize the closed conformation. Initial closing of the VFT region by agonist binding and further stabilization of the closed conformation by subsequent binding of SE modulators occurs in two steps. First, by interacting with the ECD region of TAS1R2, and second, by strengthening the hydrophobic interactions between the two lobes of ECD and lowering the free energy needed for their closure (Zhang et al., 2010).

Using a high throughput chemical screening approach and heterologous expression of the TAS1R2/TAS1R3 heteromer, several unnatural tripeptides with a novel core biaryl structure were found as potential sweet enhancers (Yamada et al., 2019). This study divided the potential molecule into three parts namely, "head and linker" which together are essential for its sweet enhancer activity, while the "tail" determines the level of activity. This approach provided some useful inputs toward synthesis of potent PAMs. Firstly, an amine incorporated at the a-position of carbonyl moiety in the tail structure interacts with the TAS1R2 subunit thereby increasing allosteric activity. Secondly, additional hydrophobic substitutions in the tail structure provided increased allosteric activity to the molecule. Lastly, distance between the head and linker and insertion of an amide bond is crucial for its synthesis. Although, their binding characteristics and allosteric mechanisms are not yet known, these observations provide a starting point to identify and synthesize new sweet PAMs in the future.

Small molecule PAMs can also bind to the transmembrane domain in class C GPCRs, in contrast to agonist which binds to the extracellular domain (Urwyler, 2011). For example, the flavonoid sweetener, neohesperidin dihydrochalcone (NHDC) binds to TMD regions to enhance the agonist induced sweet response. It interacts with a receptor binding pocket in the TMD of TAS1R3 and requires seventeen critical residues in TMDs and extracellular loop 2 for its allosteric activity (Winnig et al., 2007). These residues also contribute to cyclamate and lactisole binding sites. Among seventeen residues, eight alter receptor activation by NHDC (Q637 $7^{3.29}, \quad \mathrm{~S} 640^{3.32}, \mathrm{H} 641^{3.33}, \mathrm{Y} 699^{4.60}, \mathrm{~W} 775^{6.48}$, $\mathrm{F} 778^{6.51}, \mathrm{~L} 782^{6.55}$, and $\mathrm{C} 801^{7.39}$ ) and influence lactisole mediated inhibition. Similarly, nine of the seventeen residues $\left(\mathrm{Q} 637^{3.29}, \mathrm{H} 641^{3.33}, \mathrm{H} 721^{\mathrm{ex} 2}, \mathrm{~S} 726^{5.39}, \mathrm{~F} 730^{5.43}, \mathrm{~W} 775^{6.48}\right.$, F778 ${ }^{6.51}$, L782 $2^{6.55}$, and $\mathrm{C} 801^{7.39}$ ) mediate activation by cyclamate, while six $\left(\mathrm{Q} 637^{3.29}, \mathrm{H} 641^{3.33}\right.$, W775 $5^{6.48}, \mathrm{~F} 778^{6.51}$, $\mathrm{L} 782^{6.55}$, and $\mathrm{C} 801^{7.39}$ ) influence receptor inhibition by lactisole as well as receptor activation by cyclamate [superscript refers to the nomenclature suggested for class $C$ GPCRs by Pin et al. (2003) where first number denotes TMD region and the second number denotes residue position from the most conserved residue].

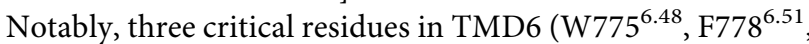
L782 ${ }^{6.55}$ ) and one in TMD7 (C801 $\left.{ }^{7.39}\right)$ of TAS1R3 were found crucial for allosteric binding, as their mutation to alanine altered the receptor's sensitivity to NHDC and cyclamate, as well as to the inhibitor lactisole (Winnig et al., 2005). Therefore, TMD6 and TMD7 $a$ helices of TAS1R3 are integral to allosteric modulation of the sweet receptor, implicating them in TAS1R2 and TAS1R3 subunit interactions and indicating an 

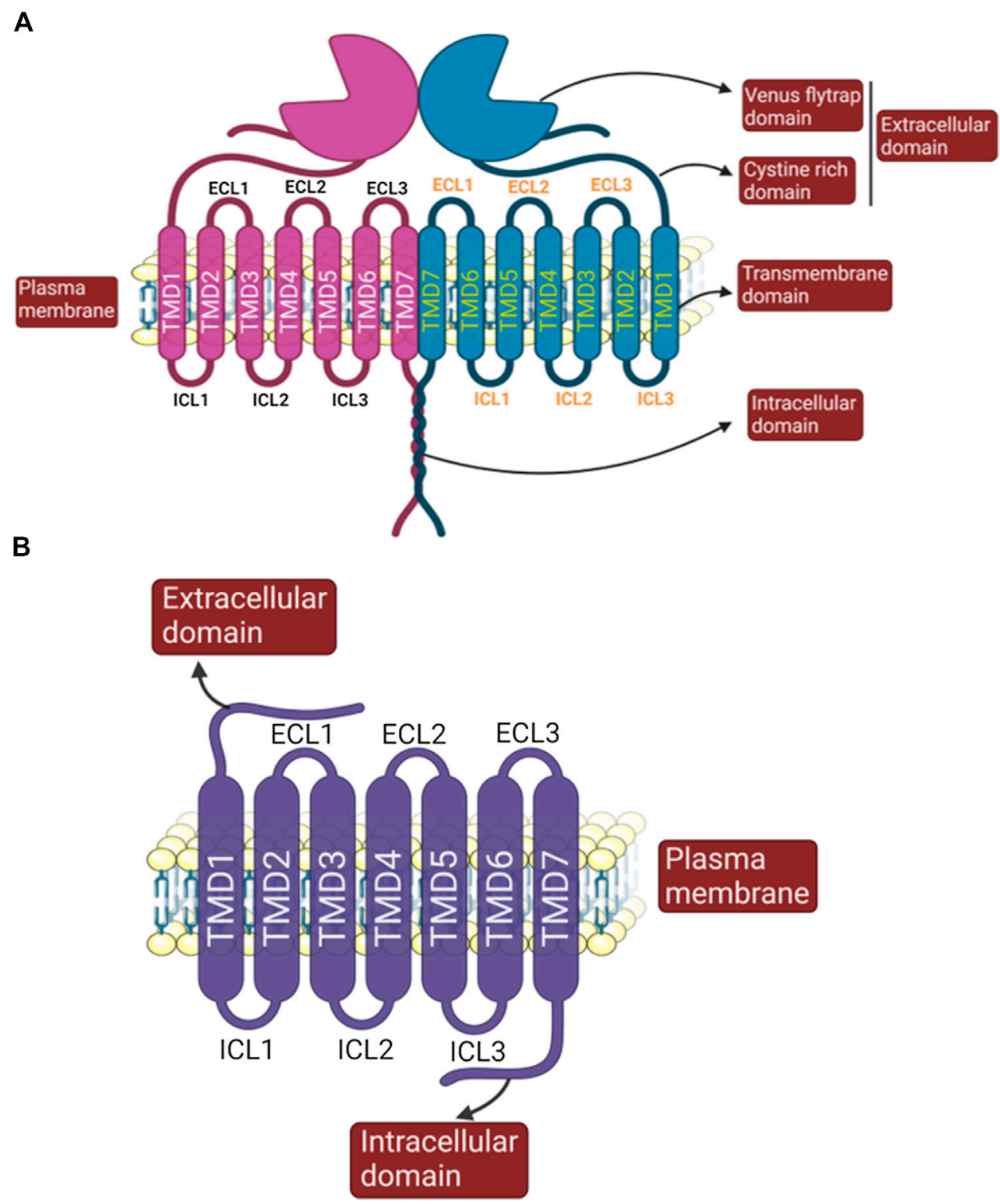

FIGURE 4 | Figure depicting basic structural features of sweet/umami/kokumi dimeric receptor (A) and monomeric bitter receptor (B) (created with BioRender. com).

important role for this structural region in the conformational changes involved in receptor activation. Furthermore, these residues are conserved across mammalian species (Cheron et al., 2019).

\section{Negative Allosteric Modulation of Sweet Receptor}

Like PAMs, negative allosteric modulators (NAM) such as lactisole and gymnemic acid bind to the TMD region of TAS1R3 and inhibit sweet substance induced responses. Lactisole, an aralkyl carboxylic acid not only inhibits sweet but also the umami receptor response in humans and presents a rare opportunity to study the structural cross talk between these two taste qualities. Using heterologous expression and mutagenesis, Jiang et al. (2005b) reported that lactisole's sweet inhibition might be mediated by its binding to TMD3, TMD5, and TMD6 of TAS1R3 and induce a conformation change which restricts the movement required to stabilize the active state. Residues A733 $3^{5.46}$ in TMD5, L798 ${ }^{7.36}$ in TMD7, and $\mathrm{R} 790^{\mathrm{ex} 3}$ in extracellular loop 3 were found to be crucially important for sensitivity to lactisole in humans (Jiang et al., 2005b). These observations were confirmed in a recent study where 2-(2,4-dichlorophenoxy)propionic acid (2,4-DP) was found to be a more potent antagonist and utilise the same residues as well as four additional ones $\left(\mathrm{H} 641^{3.37}, \mathrm{H} 734^{5.43}\right.$, 
TABLE 3 | Agonists of sweet taste receptor along with their EC50 values.

\begin{tabular}{|c|c|c|c|c|}
\hline Agonists & Nature & Binding pocket & $\mathrm{EC50}(\mathrm{mM})$ & References \\
\hline Sucrose & Natural carbohydrate & VFT (TAS1R2 and TAS1R3) & 62 & $\begin{array}{l}\text { (Li et al., 2002; Servant et al., 2010; Zhang et al., 2010; Zhang } \\
\text { et al., 2003) }\end{array}$ \\
\hline Aspertame & Peptide & VFT (TAS1R2) & 0.75 & (Li et al., 2002; Liu et al., 2011; Masuda et al., 2012) \\
\hline Neotame & Peptide & VFT (TAS1R2) & 5 & (Li et al., 2002; Masuda et al., 2012) \\
\hline Cyclamate & Sulfamate & TMD (TAS1R3) & 3.1 & (Xu et al., 2004; Jiang et al., 2005c) \\
\hline Brazzein & Protein & CRD (TAS1R3) & 0.08 & $\begin{array}{l}\text { (Li et al., 2002; Jiang et al., 2004; Ide, et al., 2009; Masuda et al., } \\
\text { 2012) }\end{array}$ \\
\hline Thaumatin & Protein & CRD (TAS1R3) & 0.005 & Masuda et al., 2012; Jiang et al., 2004 \\
\hline Monellin & Protein & VFT (TAS1R3), VFT (TAS1R2) & 0.01 & Koizumi et al., 2007; Jiang et al., 2004 \\
\hline Neoculin & Protein & VFT (TAS1R2) & 0.001 & (Jiang et al., 2004; Koizumi et al., 2007) \\
\hline Saccharin & $\mathrm{N}$ sulfonyl amide & VFT (TAS1R2) & 0.19 & (Li et al., 2002; Masuda et al., 2012; DuBois, 2016) \\
\hline Suosan, cyanosuasan & Arylurea & VFT (TAS1R2) & ND & (Tinti and Nofre, 1991; Du Bois, 2016) \\
\hline SC-45647 & Guanidinoacetic acid & VFT (TAS1R2) & 0.3 & (DuBois, 1995; Sanematsu et al., 2014) \\
\hline Sucralose & Halogenated carbohydrate & VFT (TAS1R2 and TAS1R3) & 0.06 & (Li et al., 2002; Masuda et al., 2012) \\
\hline Acesulfame $\mathrm{K}$ & Sulfamate ester & VFT (TAS1R2) & 0.54 & (Li et al., 2002; Masuda et al., 2012) \\
\hline Perillartine & Oxime, ethoxyphenyl urea, alkoxyaryl urea, & TMD (TAS1R2) & 15 & (Li et al., 2002; Servant et al., 2010) \\
\hline Dulcin & Ethoxyphenyl urea & TMD (TAS1R2) & 0.01 & (Servant et al., 2010) \\
\hline S819 & Alkoxyaryl urea & TMD (TAS1R2) & 0.025 & (Zhang et al., 2008) \\
\hline D-tryptophan & Amino acid & VFT (TAS1R2) & 2.09 & (Li et al., 2002; Masuda et al., 2012) \\
\hline Xyletol, sorbitol & Polyols & VFT (TAS1R2) & ND & (Mahalapbutr et al., 2019) \\
\hline Maltotriose, acarbose & Oligosaccharide, pseudotetrasaccharide & ND & ND & (Pullicin et al., 2017; Pullicin et al., 2019) \\
\hline
\end{tabular}

Where VFT, venus flytrap domain; TMD, transmembrane domain; ND, not determined. 
F778 $8^{6.53}$ and Q794 ${ }^{7.32}$ ) in binding to TAS1R3. Moreover, the (S)- isomer of both compounds was found to be more strongly bound to the TMD of TAS1R3 and be a more effective inhibitor [lactisole; (S)-lactisole IC50, $20 \mu \mathrm{M}$ while (R)- lactisole exerted no inhibition at this conc.; 2,4-DP: (S)-isomer was 10 fold more effective than (R)-2,4DP]. The (S)- lactisole isomer interacts with the TMD via its carboxyl group and stabilizes in only one orientation in the binding pocket that does not allow for very strong binding. In contrast, (S)-2,4- DP binds through two moieties simultaneously, a carboxyl group and an aromatic ring with two $\mathrm{Cl}^{-}$groups and stabilizes in several different orientations through hydrophobic interactions that allow stronger binding, resulting in stronger negative allosteric modulation (Nakagita et al., 2019).

These observations provide information about the relevance of structural modification in NAM compounds that could affect their interaction with the receptor. Although TMDs of TAS1R3 are the most likely regions responsible for allosteric modulation, TMDs and VFT regions of TAS1R2 cannot be ruled out completely. For example, the diuretic amiloride binds to TAS1R2 (TMD3, TMD5, TMD7) and inhibits the sweet response in a species dependent manner (Zhao et al., 2018). Further, the umami compound [monosodium glutamate (MSG)] and peptides (Glu-Asp, Glu-Glu) bind to the VFT region of TAS1R2 and inhibit the sweet induced response (Shim et al., 2015). These observations suggest that both subunits are important for allosteric activity of TAS1R2/TAS1R3 and further structural studies are required to design novel sweet allosteric modulators.

\section{UMAMI TASTE SIGNAL TRANSDUCTION MECHANISMS}

In contrast to four well-known basic human tastes (sweet, bitter, salty and sour), umami or 'savoury taste' is relatively recent and was introduced in early 2000 by Kikuna Ikeda (Ikeda, 2002) as a new seasoning element in food. The main stimulus for umami taste is the amino acid, L-glutamate present in the diet mainly in the form of MSG (Roper, 2007). Glutamate was first extracted from konbu/kombu (dried kelp of Fucus vesiculosus) and described as a "unique taste" and "very different from other tastes". The terminology "umami" comes from the Japanese word "umai" meaning "delicious." Moreover, the taste of umami is also produced by food such as mushrooms and soy sauce that contain amino acids (L-aspartate), peptides and synthetic ingredients similar to glutamate and some organic acids (Roper, 2007; Kinnamon, 2009) (Table 5).

The umami receptor (TAS1R1/TAS1R3) is a heteromeric member of the class C GPCRs, whereas most other receptors of this class exist as homodimers (Nelson et al., 2002; Temussi, 2009; Leach and Gregory, 2017). TAS1R1/TAS1R3 is the predominant umami taste receptor (Zhao et al., 2003; Behrens and Meyerhof, 2011) and the TAS1R1 subtype is critical for sensing umami taste as its deletion abolished the response to umami taste stimuli (Mouritsen and Khandelia, 2012). However, TAS1R1/TAS1R3 is not the only receptor capable of detecting umami ligands (Chaudhari et al., 2000; Kunishima et al., 2000; Li et al., 2002; Nelson et al., 2002). Studies using heterologous expression, afferent nerve recordings, and behavioral experiments have confirmed that metabotropic glutamate receptor 1 , and 4 (taste-mGluR1 and taste-mGluR4) also sense umami stimuli (Chaudhari et al., 2000; Kunishima et al., 2000; Li et al., 2002; Nelson et al., 2002). Notably, TAS1R3 knock out mice show a strongly diminished response to glutamate and sweet stimuli (Damak et al., 2003) and taste cells isolated from these mice respond to IMP and glutamate which is abolished in presence of mGluR antagonists (Pal Chaudhry et al., 2016). TAS1R1/TAS1R3 is not only activated by glutamate, but this activation is strongly enhanced in the presence of $5^{\prime}$ ribonucleotides, (inosine $5^{\prime}$ monophosphate; IMP) a response that is a hallmark of umami taste (Rifkin and Bartoshuk, 1980).

The main transduction components following the activation of TAS1R1/TAS1R3 are similar to those for sweet taste (Zhang et al., 2003), i.e., $\alpha$-gustducin (and $\gamma 13 / \beta 1$ or $\beta 3$ ), PLC $\beta 2$, IP3R and TRPM4/5. Cyclic nucleotides may also contribute to transduction of umami taste in TRCs. When taste tissue is stimulated with umami, its cyclic AMP level is decreased (Abaffy et al., 2003). However, the consequence of decreased cAMP in TRCs has not yet been fully elucidated. Both, a-transducin and a-gustducin are involved in umami taste signal transduction, as mice lacking the gene for one of these proteins showed a reduced response to this taste (He et al., 2004; Leach and Gregory, 2017). In the taste palate fungiform papillae, $\alpha$-gustducin and $\alpha$-transducin activate PDE that reduces cAMP levels. Ligand binding to the TAS1R1/TAS1R3 heterodimer, releases G $\beta \gamma$ subunits to stimulate PLC $\beta 2$, which hydrolyzes PIP2 to DAG and IP3 (Kinnamon, 2009). IP3 then activates IP3R3 which results in release of calcium ions from intracellular compartments (Clapp et al., 2001; Leach and Gregory, 2017) (Figure 3). Calcium ions activate TRPM5 and TRPM4 channels, leading to an influx of sodium ions, subsequent cell membrane depolarization, and finally release of ATP, which activates ionotropic purinergic receptors located in sensory fibers (Perez et al., 2002; Sugita, 2006). This pathway was confirmed when mice devoid of TRPM5, TRPM4, PLC $\beta 2$, and IP3R3 showed a reduced response to umami taste perception following glutamate stimuli (Damak et al., 2006; Kinnamon, 2009; Eddy et al., 2012).

\section{Structural, Molecular and Conformational Changes of Umami Receptor}

In the last decade, several in depth modeling and mutagenesis approaches have our improved structural and molecular understanding of the umami receptor. The VFT regions of both subunits of TAS1R1/TAS1R3 comprise orthosteric and allosteric ligand binding sites for umami stimuli.

Mutagenesis and molecular modeling studies reveal that the cognate agonist glutamate binds in the VFT region of the TAS1R1 subunit of TAS1R1/TAS1R3 and stabilizes the closed active receptor conformation. Moreover, four residues in the TAS1R1 VFT region (S172, D192, Y220 and E301) showed no detectable response to glutamate when they were mutated to alanine suggesting that they are critical for glutamate binding. The 
TABLE 4 | Sweet taste receptor's positive allosteric regulators with concentration (used in cell based assays in studies) and negative allosteric modulators with their IC50 values.

\begin{tabular}{|c|c|c|c|c|}
\hline $\begin{array}{l}\text { Positive allosteric } \\
\text { modulators (PAMs) }\end{array}$ & Nature & Binding pocket & Conc. (mM) & References \\
\hline SE1, SE2, SE3 & Undisclosed & VFT (TAS1R2) & 0.05 & (Servant et al., 2010; Zhang et al., 2010) \\
\hline Neohesperidin dihydrochalcone (NHDC) & Flavonoid & TMD (TAS1R3) & 0.25 & (Jiang et al., 2005c; Winnig et al., 2007) \\
\hline Unnatural tripeptides (several) & Biaryl derivative tripeptides & ND & $2-20$ & Yamada et al., 2019 \\
\hline Sodium, cholestrol & Cation, lipid & TMD (TAS1R2) & ND & Perez-Aguilar et al., 2019 \\
\hline NAMs & - & - & IC50 (mM) & - \\
\hline Lactisole & Carboxylic acid salt & TMD (TAS1R3) & 0.041 & (Jiang et al., 2005c) \\
\hline (2-(2,4-dichlorophenoxy)propionic acid) & Carboxylic acid salt & TMD (TAS1R3) & 0.006 & (Nakagita et al., 2019) \\
\hline Gymnemic acid & Triterpenoid glycoside & TMD (TAS1R3) & 6.9 & (Sanematsu et al., 2014) \\
\hline Clofibric acid & Herbicide & TMD (TAS1R3) & 1.4 & (Maillet et al., 2009; Kochem and Breslin, 2017) \\
\hline Amiloride & Diuretic & TMD (TAS1R2) & 0.87 & (Imada et al., 2010; Zhao et al., 2018) \\
\hline Umami compounds: MSG, Glu-Glu, Glu-Asp & Peptides & VFT (TAS1R2) & ND & (Shim et al., 2015) \\
\hline
\end{tabular}

Where VFT, Venus flytrap domain; TMD, transmembrane domain; ND, not determined.

glutamate binding and stabilization of the closed conformation of TAS1R1, activates the downstream signaling pathway, while TAS1R3 remains in an open (inactive) conformation. Therefore, closure of the VFT is the key event that sensitizes umami taste receptor signal transduction (Lopez Cascales et al., 2010). Apart from glutamate, other L amino acids were also found to elicit functional responses by binding to the corresponding VFT region of TAS1R1. Six residues that contributed to the acidic amino acid agonist (L-glutamate and L-alanine) responses have been identified (S148, R151, A170, E174, A302, and D435).

\section{Allosteric Modulation of Umami Receptor}

Because of significant advancement in understanding and food industry application of umami taste, its allosteric modulators are sought after. Several allosteric umami ligands have been discovered with varying potency, only a few of which have been characterized at the molecular level. The best characterized umami PAMs, the $5^{\prime}$-ribonucleotides: inosine $5^{\prime}$ monophosphate (IMP) and guanosine $5^{\prime}$-monophosphate (GMP), interact with the VFT region of the TAS1R1 subunit to enhance the glutamate induced response that is hallmark of umami taste (Table 6). IMP and GMP binding sites in the VFT are adjacent to that for glutamate binding. Mutation of four residues (H71, R277, S306, and H308) abolished the IMP/GMP induced glutamate response suggesting their involvement in allosteric binding of these nucleotides. Structurally, IMP and GMP stabilize the closed form of the TAS1R1 VFT region through electrostatic interactions and coordinate the positively charged residues that act as pincers. The ability of IMP and GMP to interact with the VFT region (as opposed to the TMD region) represents a unique mechanism of positive allosteric regulation within class C GPCRs (Urwyler, 2011).

In contrast to IMP and GMP that bind to the TAS1R1 extracellular domain, the well-known flavor compound methional and its analogs bind to the TMD region and allosterically regulate the umami receptor in a species dependent manner (Toda et al., 2018). Importantly, methional utilizes several distinct residues in different TAS1R1 transmembrane domains (TMD2-7) to act as a PAM in the human umami receptor, yet it behaves as a NAM in the mouse counterpart. This unusual phenomenon provided an opportunity to study the mechanisms of both positive and negative modulation in TAS1R1 simultaneously (Toda et al., 2018).

Construction of chimeric receptors between human (h) and mouse $(\mathrm{m})$ and their functional analysis demonstrated that the TMD of TAS1R1 is the key domain for switching the PAM/NAM activities of methional. Point mutation substitutions between these species identified four residues (h/m; F768/L769, N769/ H770, S799/T800, and S802/G803) that are collectively required to switch PAM/NAM activities. A similar mode of allosteric regulation and PAM/NAM mode switching has been reported for mGluR5 (Gregory et al., 2013) suggesting this as an unusual and distinct phenomenon of the class C GPCRs. Further, alanine scanning mutagenesis in TAS1R1 of the corresponding residues vital for the activity of other taste inhibitors (sweetener inhibitors; NHDC and cyclamate; sweet and umami taste inhibitor; lactisole) revealed three residues required for PAM (W697 $7^{4.50} \mathrm{~F} 728^{5.40}$ and F732 $2^{5.44}$ ) and a single residue $\left(\mathrm{F} 642^{3.40}\right.$ ) for NAM. These results suggest that both the PAM and NAM activities of methional are conferred by residues that are distinct from those required for the $\mathrm{PAM} / \mathrm{NAM}$ switch. Knowing that methional is an important part of food seasoning globally, these observations could help in maximizing its use in enhancing flavors along with amino acids and nucleotides.

Despite PAMs being a central focus for umami allosteric modulation, there has also been considerable research on negative allosteric modulation where lactisole emerged as a prominent NAM of the umami receptor, TAS1R2/TAS1R3. Because umami and sweet receptors share the TAS1R3 subunit, findings from studies on sweet receptor lactisole binding are relevant. A comprehensive study on the sweet receptor identified critical residues within the TMD regions $\left(\mathrm{S} 640^{3.32}, \mathrm{H}^{3} 1^{3.33}\right.$ in TMD3 and $\mathrm{F} 778^{6.51}, \mathrm{~L}_{782} 2^{6.55}$ in TMD6) of TAS1R3 required for lactisole binding pocket and showed a large effect on sensitivity to lactisole (Xu et al., 2004; Jiang et al., 2005b). Because lactisole shares structural similarity with two other classes of compound: fibrates and phenoxy-herbicides, researchers studied them to search for novel sweet/umami inhibitors (Maillet et al., 2009). The lipid lowering drug, 
clofibric acid inhibits the TAS1R3 umami receptor mediated response both in vitro and in vivo (Table 6). Like lactisole, clofibrate inhibits the umami taste from glutamate by binding with a similar affinity to TAS1R1/TAS1R3. However, its specificity against the umami receptor still needs to be validated alongside other umami taste receptors (mGluR1, mGluR4, or NMDA).

\section{TYPE 2 TASTE G PROTEIN-COUPLED RECEPTORS (BITTER RECEPTORS)}

Type 2 taste GPCRs are represented by bitter taste receptors that have a distinct subset of bitter sensing cells in type II TRCs and notably 25 bitter taste receptors (TAS2Rs) are reported to be expressed in humans (Chandrashekar et al., 2000; Devillier et al., 2015; Behrens and Meyerhof, 2018). A significant amount of work has been done to explore the diversity among TAS2Rs and their agonists in taste biology (Adler et al., 2000; Behrens and Meyerhof, 2009; Behrens and Meyerhof, 2018). Some TAS2Rs (TAS2R3, TAS2R5, TAS2R13, TAS2R50) are narrowly tuned to structurally similar bitter compounds, whereas others are broadly tuned (TAS2R10, TAS214, TAS2R46), responding to several bitter compounds. Initially it was believed that each bittersensitive type II TRC expressed every TAS2R isoform (Adler et al., 2000) but other studies suggest that TAS2Rs can be expressed differentially, allowing for possible discrimination among bitter compounds (Caicedo and Roper, 2001; Behrens and Meyerhof, 2009; Behrens et al., 2009). Please refer to figure 4B for the basic structure of the bitter receptor.

\section{Bitter Taste Signal Transduction Mechanisms}

Bitter taste is the most complex of all the five basic tastes and provides protection against ingestion of toxic substances by eliciting an innate aversive response across species (Chandrashekar et al., 2006; Behrens and Meyerhof, 2018). The TAS2Rs that mediate bitter taste perception are among $\sim 50$ TAS2Rs identified in mammals, and 25 known to be expressed in humans (Adler et al., 2000; Devillier et al., 2015; Yoshida et al., 2018). TAS2R family is the most diverse and binds to a wide range of agonists compared with the other taste GPCRs (Jaggupilli et al., 2016) (Supplementary Table 1).

TAS2Rs are distinctive among class A GPCRs in that many of them bind agonist with low apparent affinity in the micromolar range, rather than the nanomolar range (Di Pizio et al., 2016). The activation of TAS2Rs by harmless, minute amounts of bitter compounds such as those contained in most vegetables would limit the availability of food resources appearing safe for consumption and therefore could negatively affect survival. Hence, the concentration ranges at which bitter taste receptors are activated are well-balanced to allow species to maintain a healthy diet yet avoid ingestion of spoiled food containing strongly bitter ligand.

Hundreds of bitter compounds have been reported to evoke bitterness and activate human bitter receptors in different cell based assays. These bitter agonists include plant-derived and synthetic compounds such as peptides, alkaloids and many other substances (Supplementary Table 1). (Pronin et al., 2004; Meyerhof et al., 2010; Iwata et al., 2014). Some TAS2Rs are activated by a wide range of compounds, whereas others show strict specificity for a single bitter compound (Behrens et al., 2009; Sakurai et al., 2010a; Born et al., 2013). Interestingly, TAS2R31, TAS2R43, and TAS2R46 have around 85\% sequence homology, but they bind to different agonists (Brockhoff et al., 2010; Jaggupilli et al., 2016), reinforcing the idea that each TAS2R might have a unique ligand-binding pocket.

The canonical TAS2R signal transduction cascade signaling molecules shared among bitter sweet and umami receptors (Wong et al., 1996; Huang et al., 1999; Mueller et al., 2005), include the heterotrimeric $\mathrm{G}$ protein subunits ( $\mathrm{Ga}$-gustducin, Gß3, and G 13 ), (Ishimaru, 2009; Shi and Zhang, 2009), a phospholipase C (PLC 32$)$, an inositol trisphosphate receptor (InsP3R), and the TRPM5 ion channel. Upon receptor activation by bitter ligands the $G$ protein a-gustducin dissociates from its $\beta \gamma$ subunits. The latter activates PLC $\beta 2$, leading to a release of $\mathrm{Ca}^{2+}$ from IP3-sensitive $\mathrm{Ca}^{2+}$ stores, resulting in $\mathrm{Na}^{+}$influx through TRPM5 channels. This $\mathrm{Na}^{+}$ influx depolarizes the cells and causes the release of neurotransmitter ATP through gap junction hemichannels or CALHM1 ion channels (Finger et al., 2005; Chaudhari and Roper, 2010; Taruno et al., 2013) (Figure 3).

\section{Structural, Molecular and Conformational Changes of Bitter Receptors}

Classification of TAS2Rs has always been ambiguous because they were originally considered to be a distinct family (Horn et al., 2003) or grouped with the frizzled receptors (Fredriksson et al., 2003; Jaggupilli et al., 2016), but most recent analyses (Di Pizio et al., 2016) support their classification with Class A GPCRs. The ability of bitter taste receptors to interact with numerous structurally diverse substances compared to other GPCRs is remarkable and includes a wide range of drugs/antibiotics, polyphenols, bacterial metabolites, salts and metal ions (Supplementary Table 1). Therefore, exploring the criteria for identification of highly heterogeneous bitter compounds with pronounced selectivity has become a major research area. Some of these studies rely solely on in silico homology/computational modeling (Dai et al., 2011; Tan et al., 2012; Di Pizio et al., 2020; Dunkel et al., 2020) and others on in vitro genetic modification and functional assay systems (Pronin et al., 2004; Nowak et al., 2018; Jaggupilli et al., 2019).

As a group of over $\sim 50$ receptor subtypes, TAS2Rs recognize structurally diverse agonists where some are broadly tuned (TAS2R46, TAS2R14, TAS2R10, and TAS2R43) recognizing diverse agonists, while others (TAS2R1, TAS2R4, TAS2R7) show strong selectivity and narrow tuning (Liu et al., 2018; Wang et al., 2019). The agonist binding cavity in most bitter GPCRs is located deep within their transmembrane domain (TMD), with the exception of TAS2R7 in which it resides on the extracellular surface (Liu et al., 2018). TAS2Rs are also distinct in containing highly conserved TMD regions, with thirteen key residues and two motifs (LXXXR in TMD2 and 
TABLE 5 | Umami receptor agonists with their EC50 values and other pharmacological properties.

\begin{tabular}{|c|c|c|c|c|}
\hline Agonist & Nature & EC50 (mM) & Binding pocket & References \\
\hline $\begin{array}{l}\text { L-amino acids (glutamate, aspartate, } \\
\text { alanine, serine, asparagine, arginine, histidine, } \\
\text { threonine, glutamine) }\end{array}$ & Amino acids & $\begin{array}{l}3 \text { (glutamate), ND for } \\
\text { others }\end{array}$ & VFT (TAS1R1) & $\begin{array}{l}\text { (Li et al., 2002; Nelson et al., 2002; } \\
\text { Zhang et al., 2008; Toda et al., 2013) }\end{array}$ \\
\hline L-theanine & Amino acid (plant origin) & ND & VFT (TAS1R1) & (Narukawa et al., 2014) \\
\hline
\end{tabular}

VFT, venus flytrap domain; ND, not determined.

LXXSL in TMD5) that are absent in class A GPCRs, and may reflect their different activation mechanisms (Singh et al., 2011). LXXSL plays a structural role by stabilizing the helical conformation of TMD5 at the cytoplasmic end and a functional role by interacting with residues in intracellular loop 3 (ICL3) which is important for proper receptor folding and function (Singh et al., 2011). Moreover, mutation of the conserved residues in LXXSL and LXXXR motifs results in protein misfolding and poor surface expression (Singh et al., 2011; Pydi et al., 2014a).

The initial study highlighting the structure-activity relationship of bitter taste receptors was performed with receptors belonging to a subfamily of closely related TAS2Rs (Pronin et al., 2004). By physically swapping the extracellular loop 1 (ECL1) between TAS2R43 and TAS2R31, chimeric TAS2R31/TAS2R43 (ECL) gained responsiveness to the compound n-isopropyl-2methyl-5-nitrobenzenesulfonamide (IMNB), whereas the reverse chimera TAS2R31 (ECL)/ TAS2R43 lost responsiveness for IMNB. Although this report supports an important contribution of residues located within the transmembrane region of the investigated receptors, the extracellular loops appear to be of importance for agonist selectivity. This empirical finding contrasts with earlier computational studies which predicted the agonist binding site to lie within the helical bundle of TAS2Rs without particular contacts between extracellular loops and docked agonists (Floriano et al., 2006; Miguet et al., 2006).

\section{Bitter Receptor Ligand Binding Pocket}

The emergence of TAS2Rs as the most broadly tuned taste receptors might give the impression that their specific interaction with numerous agonists is because of several binding pockets that accommodate subgroups of bitter compounds. However, structure-function analysis of TAS2Rs (except for TAS2R7) has demonstrated the presence of only a single agonist binding pocket comprising the upper parts of TMD2, TMD3, TMD5, TMD6 and TMD7. The reason for their broad tuning and recognition of such a broad spectrum of agonist might most likely be attributed to the presence of an additional extracellular binding site called a "vestibular site," in addition to the orthosteric selecting as reported for TAS2R46 (Sandal et al., 2015). This two site architecture offers more ligand recognition points than a single one, and thus might help in selecting the appropriate agonists. Moreover, the presence of the vestibular site may also help to discriminate among the wide spectrum of bitter ligands.
Although broadly tuned receptors (TAS2R46, TAS2R31 and TAS2R43) have high homology in amino acid sequence, their agonist profiles only slightly overlap (Kuhn et al., 2004; Brockhoff et al., 2007; Di Pizio and Niv, 2015) which suggests the involvement of key residues at different positions in agonist specificity. Consequently, when strychinine interacting positions in TAS2R46 (residues differ at this position in TAS2R31, TAS2R43) were exchanged between these two receptors not only was the strychnine responsiveness transferred to the recipient receptor (TAS2R31, TAS2R43), but also sensitivity to additional TAS2R46 agonists (absinthin and dentaonium). Sensitivity to activation by aristolochic acid was lost in the mutant receptors (Brockhoff et al., 2010). This experimental evidence supports the presence of a common agonist binding pocket and agrees with other studies on TAS2R16, TAS2R14 and TAS2R7 receptors (Sakurai et al., 2010a; Sakurai et al., 2010b; Thomas et al., 2017; Liu et al., 2018; Nowak et al., 2018).

Recent studies used homology modeling and mutagenesis to elucidate the nature of the ligand binding pocket in TAS2R7, TAS2R14 and TAS2R16 receptors (Thomas et al., 2017; Liu et al., 2018; Nowak et al., 2018). They reported that the binding pocket is flexible and wide open to accommodate molecules of diverse size and shape, and thus permits chemical modifications among agonists as well (Thomas et al., 2017; Liu et al., 2018; Nowak et al., 2018). Although the molecular basis for the promiscuity of bitter receptors is attributed to their apparent flexible spacious binding site, future work elucidating the contact points between TAS2Rs binding site residues and its agonists in terms of additional binding locations is required.

\section{Bitter Receptors Ligand Binding Domain and Amino Acid Residues}

A majority of the TAS2R studies based on molecular modeling, mutagenesis and heterologous expression systems (Biarnes et al., 2010; Brockhoff et al., 2010; Tan et al., 2012; Nowak et al., 2018; Shaik et al., 2019) suggest that the ligand binding pocket is formed by several key residues in most TMDs (TMD1, TMD2, TMD3, TMD5, TMD6 and TMD7), with the exception of TMD4.

Studies show similarities as well as differences regarding residues and positions involved in agonist-receptor interactions. However, most of them agree that besides position $\mathrm{N}^{3.36}$ in TMD3 (superscript as per BallestrosWeinstein nomenclature for class A GPCRs) (Ballesteros and Weinstein, 1995) and other residues $\left(\mathrm{L}^{3.32}, \mathrm{~L}^{3.33}\right.$, and $\left.\mathrm{E}^{3.37}\right)$ in its close proximity, play a role in agonist activation of several broadly 
TABLE 6 | Umami receptor allosteric modulators with conc. used in cell based assays and other pharmacological properties.

\begin{tabular}{|c|c|c|c|c|}
\hline Allosteric modulators & Nature & $\begin{array}{l}\text { Conc. } \\
\text { (mM) }\end{array}$ & $\begin{array}{l}\text { Binding } \\
\text { pocket }\end{array}$ & References \\
\hline IMP/GMP & Nucleotide & 1 & VFT (TAS1R1) & $\begin{array}{l}\text { (Li et al., 2002; Nelson et al., 2002; Zhang et al., } \\
\text { 2008) }\end{array}$ \\
\hline Cyclamate & $\begin{array}{l}\text { Sodium } \\
\text { cyclohexylsulfamate }\end{array}$ & 8 & TMD (TAS1R3) & (Xu et al., 2004) \\
\hline Methional (3-methylsulfanylpropanal) & - & 0.12 & TMD (TAS1R3) & (Toda et al., 2018) \\
\hline Lactisole (2-4-methoxyphenoxy propionic acid) & Carboyxlic acid salt & 5 & TMD (TAS1R3) & (Xu et al., 2004) \\
\hline Clofibric acid (4- chlorophenoxy)-2-methylpropanoic & Herbicide acid & 4 & TMD (TAS1R3) & (Maillet et al., 2009; Kochem and Breslin, 2017) \\
\hline
\end{tabular}

acid

Where VFT, Venus flytrap domain; TMD, transmembrane domain

tuned TAS2Rs (TAS2R1, TAS2R16, TAS2R30, TAS2R38, TAS2R46) (Pronin et al., 2004; Biarnes et al., 2010; Brockhoff et al., 2010; Sakurai et al., 2010b; Dai et al., 2011). In contrast, for the narrowly tuned TAS2R7, one position in TMD3 $\left(\mathrm{H}_{9} 4^{3.37}\right.$ ) and another in TMD7 (E264 ${ }^{7.32}$ ) were found crucial for metal ion binding (Wang et al., 2019). Mutagenesis and molecular modeling revealed that these two residues contribute to the metal ion binding pocket in TAS2R7. Moreover, metal ions bind distinctively to residues lining the binding pocket and interestingly, the presence of calcium in the assay solution appears to affect the TAS2R7 response to metal ions. It is not clear how calcium affects metal ion binding to TAS2R7, but it might work cooperatively with certain ions and not others. Future studies focusing on structural interactions between the receptor and metal ions will provide further insights into how they activate the receptor.

In TMD2, two studies suggest that position $\mathrm{N}^{2.61}$ is critical for binding in TAS2R1 (Singh et al., 2011) and TAS2R46 (Brockhoff et al., 2010). Likewise, in TMD7, position $265^{7.39}$ is implicated in binding to TAS2R46 (E265) and TAS2R1 (I263) (Dai et al., 2011). In TMD5, position $\mathrm{H}^{5.43}$ is implicated in binding in TAS2R16 and $\mathrm{E}^{5.46}$ in TAS2R1 (Dai et al., 2011) while, in TMD7, position $\mathrm{E}^{7.32}$ was crucial for metal ion binding (Wang et al., 2019). These residues represent putative contact points for agonist interaction and form a pattern in being spaced one helical turn from each other.

Recent mutagenesis studies (Nowak et al., 2018; Di Pizio et al., 2020) performed in broadly tuned TAS2R14 with agonists (aristolochic acid, picrotoxinin, thujone) found several residues in TMDs to be involved in agonist binding. However, in contrast to TAS2R10 (Born et al., 2013) and TAS2R46 (Brockhoff et al., 2007), mutation of TAS2R14 did not result in complete loss of function for all agonists but a varied reduction in responsiveness or selectivity toward agonists. Among several mutants, only mutation of W89A resulted in complete loss of responsiveness against picrotoxinin while others showed more subtle agonist selective changes. This indicates that TAS2R14 is not streamlined for the most sensitive detection of selected agonists, but rather tailored to detect numerous diverse agonists, with comparatively lower apparent affinity.

The binding characteristics of bacterial acyl homoserine lactones (AHLs) on TAS2Rs (TAS2R4, TAS2R14 and TAS2R20) suggest the presence of a single orthosteric site situated close to the extracellular surface and reinforce the significant role of the extracellular loop structure (ECL2) in TAS2R ligand binding and activation (Jaggupilli et al., 2018). The crucial AHL binding residues in TAS2R4 and TAS2R14 are predominantly located in the ECL2, while in TAS2R20 they are present in TMD3 and TMD7 helices. The ECL2 residues, N165 in TAS2R4, and R160 and K163 in TAS2R14 were found crucial for lactone binding. In contrast, TAS2R20 residues W88 (TMD3) and Q265 (TMD7) are essential for agonist binding (Pydi et al., 2014c; Zhang et al., 2017; Jaggupilli et al., 2018). In addition, the hydrophobic amino acids in the three TAS2Rs are considered important in directing the orientation of the hydrophobic acyl chains of lactones that facilitate receptor activation.

The transmembrane domain in GPCRs is composed mainly of hydrophobic amino acids accommodated in the plasma membrane. Therefore, hydrophobic properties of the receptor binding pocket are important for any membrane accessible agonist. Hydrophobic residues in TMD3 and TMD7 of TAS2R16 are important in forming a wide ligand-binding pocket (Thomas et al., 2017) that accommodates larger ligands like the $\beta$-glycosides. By using salicin analogs as TAS2R16 novel agonists (differ structurally to salicin in $\beta$-glucoside core constituents), several critical residues were identified that are required for signaling. Interestingly, these were identical to the residues critical for salicin signaling, except for W261, which was not required for activation by the analog 4-NP- $\beta$-mannoside. Importantly, all these residues are in the TMD helices or intracellular face of the receptor, consistent with classical GPCR signal transduction. These results suggest that larger ligands bind to the wide binding pocket of TAS2R16 on the extracellular side, and then their signal is transduced via conserved residues on the intracellular side. This can account for the broad spectrum of ligand recognition conferred by TAS2R16.

Unlike broadly tuned receptors, narrowly tuned ones like TAS2R7 show two different types of critical residue in ligand binding. The first type includes D86, W170 and S181 that are agonist independent and their mutation significantly reduces the ability of TAS2R7 to bind agonist, while a second group consisting of D65 and W89 are selective for quinine and enhance binding to a specific category of ligand (Liu et al., 2018).

Despite the variation in the amino acid type and location important for agonist binding among receptors of the bitter 
family, for the most part, ligand binding pockets are present on the extracellular surface of TMDs or on ECL2. The function of the residues at these binding pockets is dictated by multiple factors that include the type of ligand, the movements in TMDs, and the associated movement of ECL2 to accommodate the ligand. Structure-function studies have identified a conserved KLK/R motif in the intracellular carboxyl terminal domain of 19 TAS2Rs that is critical for cell surface expression, trafficking and receptor activation (Upadhyaya et al., 2015; Jaggupilli et al., 2016).

\section{Agonist, Antagonist Binding and Modulation of Bitter Receptors}

In simple pharmacological terms an antagonist is a ligand that inhibits the biological response induced by an agonist and does not induce any response of its own, while a ligand that reduces the constitutive/basal activity of a GPCR is considered an inverse agonist. An antagonist acts as a competitive inhibitor to block receptor activity. Large numbers of agonists have been identified for bitter receptors, but few antagonists have been found so far (Table 7). Finding an antagonist/inhibitor for bitter taste would not only help in understanding the TAS2R mechanism of signal transduction but have potential use in foods to overcome unwanted bitterness in consumer products. Such bitter blockers have been proposed to increase the palatability of bitter tasting food and beverages, increase the compliance in taking bitter tasting drugs, especially children's formulations and reduce or prevent off-target drug effects in extra-oral tissues (Clark et al., 2012).

To date $\sim 12$ bitter inhibitors have been reported to interact with only 10 TAS2Rs subtypes (Table 5) by binding to transmembrane domains in a similar manner to agonist. GIV3727 (4-(2,2,3-trimethylcyclopentyl) butanoic acid) was the first TAS2R antagonist discovered and to be well characterized structurally (Slack et al., 2010) that acts as an orthosteric competitive antagonist for TAS2R31. It competes with the acesulfame $\mathrm{K}$ agonist both in vitro and in vivo. GIV3727 is moderately selective because it inhibits multiple bitter receptors including, TAS2R4, TAS2R40 and TAS2R43. Homology modeling revealed that the $-\mathrm{COOH}$ group in GIV3727 is important for ligand-receptor interactions as its replacement with an ester or the corresponding alcohol abolished its antagonist activity. Moreover, a mutagenesis study in TAS2R31 and TAS2R43 revealed residues K265 ${ }^{7.39}$ and $268^{7.39}$ in TMD7 to be crucial for its antagonistic activity (Slack et al., 2010). Similarly, another non-selective inhibitor, probenecid (p-(dipropylsulfamoyl) benzoic acid) was found to act as NAM of TAS2R16 activity and inhibits TAS2R38 and TAS2R43 as well (Greene et al., 2011). Two point mutations, P44T and N96T in TMD3 of hTAS2R16 were found to significantly suppress the ability of probenecid to inhibit salicin activity. Hydrophobicity seems important for their pharmacological activity as observed for both probenecid and GIV3727. The sesquiterpene lactone, $3 \beta$ hydroxydihydrocostunolide (3HDC) is an interesting bitter blocker as it acts as a competitive antagonist of TAS2R46,
TAS2R30, TAS2R40, yet activates TAS2R4, TAS2R10, TAS2R14 and TAS2R31 as an agonist (Brockhoff et al., 2011).

Similarly, various flavonones were also noted as antagonists for TAS2R31, TAS2R39 with varying efficacy. Taken together most of the currently known antagonists are non-selective and there is an urgent need for studies that focus on selective antagonists of major broadly tuned TAS2Rs (such as TAS2R10, TAS2R14, TAS2R16 and TAS2R46). In order to target bitterness in terms of food industry needs, potential peptide inhibitors from different protein sources such as hen protein hydrolysates (inhibits TAS2R4, TAS2R7, TAS2R14) and beef proteins (inhibits TAS2R4) (Zhang et al., 2018; Xu et al., 2019) are reported to be effective. Several umami glutamyl peptides isolated from soyabean have been found to act as non-competitive allosteric inhibitors of TAS2R16 against the salicin induced response (Kim et al., 2015).

\section{Constitutive Activity of Bitter Receptors}

A phenomenon in GPCR activity is that of constitutive activity, essentially an active state occurring in the absence of agonist which has been demonstrated in more than 60 GPCRs (Seifert and Wenzel-Seifert, 2002). It is the production of a second messenger or downstream signaling by a receptor in ligand independent manner. Constitutive activity provides another possibility for taste inhibitor discovery using inverse agonists. Inverse agonists can inhibit both agonist-dependent and agonist-independent activity, while antagonists can inhibit only agonist-dependent activity (Chalmers and Behan, 2002). Interestingly, some mutations in GPCRs can lead to constitutive activity and receptors with this characteristic (including constitutively active mutants or CAM) are important tools to investigate new bitter inhibitors. Although constitutive activity has not been observed naturally in TAS2Rs, when induced by mutation these receptors provide a useful means to investigate the relationship between an active receptor conformation and inverse agonist pharmacology.

Molecular modeling and functional assays report five CAMs critical residues for TAS2Rs, one in TMD7 $\left(\mathrm{S} 285^{7.47}\right)$ and four others in intracellular loop 3 (H214A, Q216A, V234A, and M237A) (Pydi et al., 2014a; Pydi et al., 2014b). Of the five CAMs, only the TAS2R4 with H214A mutation shows a 10 fold increase in constitutive activity. This histidine residue is highly conserved in most TAS2Rs. Mutation of $\mathrm{H} 214$ (H214A) helped in finding two new inverse agonists (GABA and ABA; Table 7) (Pydi et al., 2015). Similar pharmacological approaches can be used to generate mutants of all TAS2Rs to screen for their inverse agonist/bitter taste blockers. However, for better characterization and interpretation of TAS2Rs, future in vivo studies should be performed to understand the functional relevance of these CAMs. At the same time, it is worth noting that the potential presence of endogenous agonists makes it difficult to determine the true constitutive activity of GPCRs including TAS2Rs (Devillier et al., 2015). 


\section{KOKUMI SENSATION SIGNAL TRANSDUCTION}

In addition to the five basic tastes, sensations beyond these add another dimension to taste perception. One such example is "kokumi" that is distinct from the other five tastes in that it does not have a taste as such but rather induces a sensation of "mouthfulness," depth, thickness and aftertaste in the flavors. Although, this flavor has been used historically and is well recognized in Japanese cuisine, it was first characterized by Ueda et al. (1990) who isolated a kokumi taste substance from water extracts of garlic and onion and identified, $\gamma$-glutamylcysteinylglycine or glutathione (GSH) as the main active ingredient of kokumi flavor (Ueda et al., 1990; Ueda et al., 1997; Dunkel et al., 2007). GSH is abundantly present in food-grade yeast extract and has been used to make foods more flavoursome.

Kokumi signal transduction was unknown until CaSR expression was reported in a subpopulation of taste cells in mice and rats that suggested it could function as a taste receptor for calcium and amino acids (San Gabriel et al., 2009; Bystrova et al., 2010). However, its apparent role in kokumi stimuli detection was not confirmed. Ohsu et al. (2010) for the first time reported that kokumi peptides (GSH, $\gamma$-Glu-Val-Gly and various $\gamma$-glutamyl peptides; Table 8) signal through CaSR and can synergise with sweet, salty, and umami taste qualities to impart an augmented kokumi sensation, i.e., increased depth of flavor which was further complemented by later studies (Maruyama et al., 2012; Kuroda and Miyamura, 2015). By using heterologous expression systems and human sensory analysis these studies demonstrated that kokumi peptides impart kokumi sensation to sweet, salty and umami taste via CaSR as the kokumi component was specifically suppressed in the presence of the CaSR-specific NAM NPS-2143. To further validate this idea, Maruyama et al. (2012) identified a distinct population of taste cells expressing CaSR in mouse lingual tissue which did not express either sweet or umami receptors. Notably, these cells are specifically responsive to kokumi substances and elicit a $\mathrm{Ca}^{2+}$ response to focally applied kokumi stimuli in mouse lingual slices. Moreover, this response was inhibited in the presence of NPS-2143. These findings support the idea that CaSR mediates kokumi sensation effects in TRCs.

More recently, kokumi peptides have been found to have an extraoral physiological role in the gastrointestinal tract where they stimulate secretion of hormones (cholecystokinin and glucagon-like peptide1 by activating CaSR (Depoortere, 2014; Yang et al., 2019). However, future studies with tissue specific deletion of CaSR in taste buds would be helpful in delineating its role in taste physiology.

CaSR involvement in taste is a relatively recent discovery, but its central role in extracellular calcium homeostasis in mammals is well recognised (Brown et al., 1993; Brown, 2013). Diverse ligands activate CaSR, including cations $\left(\mathrm{Ca}^{2+}\right.$ and $\left.\mathrm{Gd}^{3+}\right)$, peptides, polyamines (Brown and MacLeod, 2001) and amino acids (Conigrave et al., 2000; Conigrave and Hampson, 2006) (Table 8). Unlike other taste modalities (sweet, bitter and umami), CaSR-ligand binding and recruitment of $\mathrm{G}$ protein results in the activation of an intricate, amplifying signaling network which initiates numerous intracellular functions. The functional diversity of CaSR results from its ability to activate multiple Ga proteins (Gq/11, Gi/o, G12/13 and Gs) (Magno et al., 2011; Conigrave and Ward, 2013) which subsequently affect multiple signaling pathways related to the pathophysiology of parathyroid hormone secretion, cancer and metastasis (Kelly et al., 2007; Wettschureck et al., 2007; Mamillapalli et al., 2008).

Kokumi substrates activate CaSR and transmit their signal through Gaq/11 proteins which further activate PLC $\beta$ that results in release of intracellular $\mathrm{Ca}^{2+}$ store through activation of IP3 receptor channels in the ER. Whether the kokumi pathway strictly relies on Gaq/11 protein or can also use Ga-gustducin, like other taste modalities for downstream signaling, is still unknown (Figure 3). The growing number of reports on kokumi flavor signal transduction are shedding light on its potential use as a flavor enhancer.

\section{Structural, Molecular and Conformational Changes of Kokumi Receptor}

CaSR belongs to the class C GPCR. Within this class, CaSR and metabotropic glutamate receptors (mGluRs) are known to function as disulfide-linked homodimers (Bai et al., 1998; Ward et al., 1998; Pidasheva et al., 2006) (Figure 4A). Structurally, the human CaSR is similar to sweet and umami taste receptors but differs in being a homodimer instead of a heterodimer (Hendy et al., 2013). The ECD of CaSR not only senses nutrients $\left(\mathrm{Ca}^{2+}, \mathrm{L}-\mathrm{Phe}\right.$ and polypeptides; Table 8) and allows ligand to modulate CaSR cooperatively, but is also required for its dimerization (Ray et al., 1999; Zhang et al., 2014). Binding of $\mathrm{Ca}^{2+}$ and other ligands to the ECD changes the conformation of the seven transmembrane domains, causing alterations in the intracellular loops and the intracellular domain (ICD), which further trigger downstream signaling pathways (Brown et al., 1975). The ICD is relatively diverse among species and participates in controlling CaSR signaling in multiple ways by modulating receptor expression, trafficking and desensitization (Gama and Breitwieser, 1998; Ward, 2004; Huang et al., 2006).

Homology modeling, mutagenesis and heterologous expression revealed distinct and closely located binding sites for $\mathrm{Ca}^{2+}$ and aromatic L-amino acids, in VFT and the cleft of the VFT, respectively (Silve et al., Conigrave et al.,2000; Huang et al., 2009). Notably, four putative $\mathrm{Ca}^{2+}$ binding sites of varying affinity have been predicted in the VFT of the CaSR and in which the interaction between site 1 and the other three sites plays a central role in positive cooperativity in sensing $\mathrm{Ca}^{2+}$ (Zhang et al., 2014). Besides $\mathrm{Ca}^{2+}$, aromatic L amino acids (L-Trp, L-Phe) also activate the CaSR by binding adjacent to the VFT region through three serine and one threonine residue (S169/S170/S171/T145). Interestingly, the double mutation $\mathrm{T} 145 / \mathrm{S} 170$ was found to selectively impair L amino acid (Phe, Trp, His) sensing of CaSR, while $\mathrm{Ca}^{2+}$ sensing remained intact (Mun et al., 2004; Mun et al., 2005).

The recent crystal structure of the entire extracellular domain of CaSR (Geng et al., 2016) identified four novel $\mathrm{Ca}^{2+}$ binding 
sites in each protomer of the homodimer including one at the homodimer interface which does not correspond to any of the sites reported previously by Huang et al., (2007). It is unclear why these additional calcium binding sites were not found in earlier studies. This might be due to the different expression systems used, crytallization conditions and methods of analysis. The conditions of the more recent studies may have stabilised an active conformational state in which these calcium sites become available (Geng et al., 2016). Among these four $\mathrm{Ca}^{2+}$-binding sites, site 4 seems most relevant to receptor activation as it directly participates in the active CaSR conformation. Moreover, a previously reported natural mutation G557E (Hendy et al., 2009) reduced the potency of $\mathrm{Ca}^{2+}$ possibly by affecting backbone conformation, thereby weakening the affinity of $\mathrm{Ca}^{2+}$ for this site. This confirms that $\mathrm{a} \mathrm{Ca}^{2+}$ ion at site 4 stabilizes the active conformation of the receptor by facilitating homodimer interactions between the membrane proximal LBD2 region and CRD of CaSR.

The most interesting aspect of $\mathrm{Ca}^{2+}$ and $\mathrm{L}$-amino acid interplay was reported by Zhang et al. (2014) who studied L-Phe binding characteristics by monitoring intracellular $\left[\mathrm{Ca}^{2+}\right]_{\mathrm{i}}$ oscillations in living cells and performing molecular dynamic simulations. Their findings supported a previous observation that the L-Phe binding pocket is adjacent to the $\mathrm{Ca}^{2+}$ binding site 1 . Importantly, by binding to this site, L-Phe influences all $\mathrm{Ca}^{2+}$ binding sites in the VFT region and enhances CaSR functional cooperativity through positive heterotropic cooperativity to $\mathrm{Ca}^{2+}$. Moreover, the dynamic communication of L-Phe at its predicted binding site in the hinge region with the $\mathrm{Ca}^{2+}$ binding sites not only influences the adjacent $\mathrm{Ca}^{2+}$ binding site 1 , but also globally enhances cooperative activation of the receptor in response to alterations in extracellular $\mathrm{Ca}^{2+}$.

The crystal structures (Geng et al., 2016) of the entire ECD region of CaSR in the resting and active conformations have provided additional information about the dynamics between calcium and L-amino acid binding (Geng et al., 2016). Most importantly, by using L-Trp, the study provided direct evidence that L-amino acids are CaSR co-agonists, and they act concertedly with $\mathrm{Ca}^{2+}$ to achieve full receptor activation. Several lines of evidence support this contention: 1) L-Trp binds at the interdomain cleft of the VFT, which is a canonical agonistbinding site for class C GPCRs (Kunishima et al., 2000; Muto et al., 2007; Geng et al., 2016) and shares a common receptorbinding mode with the endogenous agonists (amino acids or their analogs) of mGluR and $\mathrm{GABA}_{\mathrm{B}}$ receptors, (Kunishima et al., 2000; Tsuchiya et al., 2002; Muto et al., 2007; Geng et al., 2016). 2) L-Trp interacts with both LBD1 and LBD2 in ECD to facilitate its closure, a crucial first step during CaSR activation. In contrast, no $\mathrm{Ca}^{2+}$ ion is found at the putative orthosteric agonist-binding site to induce domain closure. 3) Mutations of L-Trp-binding residues (S147A, S170A, Y218A, and E297K) severely reduced $\mathrm{Ca}^{2+}$ induced IP accumulation and intracellular $\mathrm{Ca}^{2+}$ mobilization (Zhang et al., 2002; Silve et al., 2005), indicating that $\mathrm{L}-\mathrm{Trp}$ is required for a $\mathrm{Ca}^{2+}$ induced receptor response. Notably, the presence of extracellular $\mathrm{Ca}^{2+}$ above a threshold level is required for amino-acid-mediated CaSR activation, amino acids increase the sensitivity of the receptor toward $\mathrm{Ca}^{2+}$.
Taken together, amino acids and $\mathrm{Ca}^{2+}$ ions act jointly to trigger CaSR activation.

Knowing that aromatic L-amino acids (Trp, Phe, His) are important tastants in kokumi flavor, CaSR becomes more relevant for taste biology. Moreover, the kokumi tripeptide, glutathione (GSH) and glutamyl peptide are suggested to bind allosterically to CaSR at the same site as L-amino acids (Wang et al., 2006; Broadhead et al., 2011) and enhance its activity in the presence of $0.5-1 \mathrm{mM}$ free calcium, thereby acting as a positive allosteric modulator. In addition, an ECD crystal structure might help to explain structural and molecular details of the GSH binding pocket such as the nature of critical residues and their binding characteristics. In view of recent reports of calcium emerging as taste modifier, it would be worth investigating how GSH and $\mathrm{Ca}^{2+}$ operate in kokumi human perception.

\section{Allosteric Modulation of Calcium-Sensing Receptor}

Classically CaSR is known to be involved in pathophysiology of parathyroid and renal related diseases by sensing calcium ions in extracellular fluid (Brown, 2007). Research on related therapeutic applications has identified several classes of PAMs and NAMs that modulate CaSR agonist sensitivity. More recently this has been applied to kokumi taste signal transduction.

\section{Endogenous Modulators (L-amino Acids, Anions and Glutathione Analogs)}

Several studies based on molecular modeling and mutagenesis report $\mathrm{L}$-amino acids (L-Phe, $\mathrm{L}-\mathrm{Tyr}, \mathrm{L}-\mathrm{His}$ and $\mathrm{L}$-Trp) as PAMs because they enhance the $\mathrm{Ca}^{2+}$ induced response of CaSR. Aromatic L-amino acids bind in the VFT domain (Mun et al., 2004) and require a highly conserved five residue binding motif (S147, S170, D190, Y218 and E297) (Conigrave and Hampson, 2006; Geng et al., 2016). Among these residues, E297 was identified through the natural mutation E297K as essential for structural and functional activity (Table 8) (Pollak et al., 1993; Bai et al., 1998; Conigrave et al., 2000; Zhang et al., 2002; Mun et al., 2004).

As recently identified NAMs, anions $\mathrm{SO}_{4}{ }^{2-}$ and $\mathrm{PO}_{4}{ }^{3-}$ are important modulators of the $\mathrm{Ca}^{2+}$ induced response. They bind in the VFT region and act as moderate NAMs for CaSR activity (Geng et al., 2016; Centeno et al., 2019). Based on anomalous difference maps, four anion-binding sites were identified in the inactive and active CaSR ECD structures. Sites 1 and 3 are located above the interdomain cleft in LBD1, while site 4 lies in the LBD2 region. Sites 1 and 3 appear to stabilize the inactive conformation while site 2 , which is present in both active and inactive conformations appears important for receptor function as mutation in its residues (R66H, R69E, and S417L) abolished the $\mathrm{Ca}^{2+}$ induced response. In addition, each protomer structure contains one $\mathrm{Ca}^{2+}$ ion and three $\mathrm{SO}_{4}{ }^{2-}$ ions which together contribute to the structural integrity of the receptor (Geng et al., 2016). Taken together, anions along with $\mathrm{Ca}^{2+}$ and amino acids are involved in an intricate interplay for CaSR activation to maintain conformational equilibrium between inactive and active states. 
TABLE 7 | Bitter taste receptor inhibitors with their IC50 values and other pharmacological properties.

\begin{tabular}{|c|c|c|c|c|c|}
\hline Antagonist & $\begin{array}{l}\text { Mode of } \\
\text { action }\end{array}$ & Bitter receptors & Tested agonists & IC50 ( $\mu \mathrm{M})$ & References \\
\hline \multirow[t]{4}{*}{ GIV3727or 4-(2,2,3-trimethylcyclopentyl) butanoic acid } & Competitive orthosteric inhibitor & 31 & acesulfameK & 6.4 & (Slack et al., 2010) \\
\hline & & 43 & Aristolochic acid & 11.33 & \\
\hline & & 4 & Cochicine & 108 & \\
\hline & & 40 & Cohumulone & 6.24 & \\
\hline Gamma-aminobutyric acid (GABA) & Orthosteric inhibitor & 4 & Quinine & 3.2 & (Pydi et al., 2014b) \\
\hline \multirow[t]{5}{*}{ 3ß-hydroxydihydrocostunolide (3HDC) } & ND & 46 & Absinthin & 14.1 & (Slack et al., 2010; Brockhoff et al., 2011) \\
\hline & & & Andrographolide & 4.9 & \\
\hline & & & Denatonium & 6.8 & \\
\hline & & & Picrotoxinin & 4.7 & \\
\hline & & & Strychnine & 15.3 & \\
\hline \multirow[t]{5}{*}{ 3-hydroxypelenolide(3HP) } & ND & & Absinthin & 57.8 & (Brockhoff et al., 2011) \\
\hline & & & Andrographolide & 44.5 & \\
\hline & & & Denatonium & 51.4 & \\
\hline & & & Picrotoxinin & 22.9 & \\
\hline & & & Strychnine & 84.9 & \\
\hline Probenecid & Allosteric inhibitor & 16 & Salicin & 292 & (Greene et al., 2011) \\
\hline Sakuranetin & ND & 31 & Saccharin & 5.5 & (Fletcher et al., 2011) \\
\hline 6-Methoxysakuranetin & ND & 31 & Saccharin & 10.2 & (Fletcher et al., 2011) \\
\hline Jaceosidin & ND & 31 & Saccharin & 11.7 & (Fletcher et al., 2011) \\
\hline \multirow[t]{2}{*}{ 6,3'-dimethoxyflavanone } & ND & 39 & Epicatechin gallate (ECG) & 4075 & (Roland et al., 2014) \\
\hline & & & Denatonium & 240 & \\
\hline 6-Methoxyflavanone & ND & 39 & Epicatechin gallate (ECG) & 479 & (Roland et al., 2014 \\
\hline N,N-bis(carboxymethyl)-I-lysine(BCML) & ND & 4 & Quinine & 0.059 & (Pydi et al., 2014b) \\
\hline$( \pm)$ abscisic acid (ABA) & ND & 4 & Quinine & 34.4 & (Pydi et al., 2015) \\
\hline
\end{tabular}

$N D$, not determined. 
TABLE 8 | Kokumi sensation receptor agonists, allosteric modulators with concentrations used in cell based assays.

\begin{tabular}{|c|c|c|c|c|}
\hline Agonist & Type/nature & $\begin{array}{l}\text { Conc. (mM unless } \\
\text { stated otherwise) }\end{array}$ & Binding pocket & References \\
\hline $\mathrm{Ca}^{2+}$ & Orthosteric agonist/cation & $1^{\mathrm{a}}$ & VFT & (Brown et al., 1993; Conigrave et al., 2000; Breitwieser, 2006) \\
\hline $\mathrm{Mg}^{2+}$ & Orthosteric agonist/cation & $10^{\mathrm{a}}$ & VFT & (Brown et al., 1993) \\
\hline $\mathrm{Gd}^{3+}$ & Orthosteric agonist/cation & $0.02^{\mathrm{a}}$ & VFT & (Brown et al. 1993) \\
\hline $\mathrm{Al}^{3+}$ & Orthosteric agonist/cation & 0.5 & VFT & (Brown et al., 1993) \\
\hline $\mathrm{Sr}^{2+}$ & Orthosteric agonist/cation & 0.5 & VFT & (Brown et al., 1993) \\
\hline $\mathrm{Mn}^{2+}$ & Orthosteric agonist/cation & 0.5 & VFT & (Brown et al., 1993) \\
\hline $\mathrm{Ni}^{2+}$ & Orthosteric agonist/cation & 0.5 & VFT & (Brown et al., 1993) \\
\hline $\mathrm{Ba}^{2+}$ & Orthosteric agonist/cation & 0.2 & VFT & (Brown et al., 1993) \\
\hline Spermine & Orthosteric agonist/polyamine & $0.15^{\mathrm{a}}$ & VFT & Quinn et al., 1997) \\
\hline Spermidine & Orthosteric agonist/polyamine & $0.002^{\mathrm{a}}$ & VFT & (Nemeth et al., 2018) \\
\hline Neomycin & Orthosteric agonist/aminoglycoside antibiotic & $0.06^{a}$ & VFT & (Katz et al., 1992) \\
\hline Gentamicin & Orthosteric agonist/aminoglycoside antibiotic & $0.15^{\mathrm{a}}$ & VFT & Katz et al., 1992) \\
\hline Kanamycin & Orthosteric agonist/aminoglycoside antibiotic & 0.1 & VFT & (Katz et al., 1992) \\
\hline Amyloid $\beta$-peptides & Orthosteric agonist/Peptide & $0.001-0.04$ & - & (Ye et al., 1997) \\
\hline Poly-Lysine & Orthosteric agonist/peptide & $0.03 \mu \mathrm{M}^{\mathrm{a}}$ & VFT & (Brown et al., 1991; Nemeth et al., 2018) \\
\hline Poly L-arginine & Orthosteric agonist/peptide & $0.004 \mu \mathrm{M}^{\mathrm{a}}$ & VFT & Brown et al., 1991; Nemeth et al., 2018) \\
\hline Lysozyme & Agonist/protein & $0.59^{\mathrm{a}}$ & ND & (Yamamoto et al., 2020) \\
\hline Thaumatin & Agonist/protein & $0.07^{\mathrm{a}}$ & ND & (Yamamoto et al., 2020) \\
\hline Aromatic L-amino acids (Trp, Phe, His, Ala, Ser) & PAMs & 10 & VFT & (Conigrave et al., 2000; Mun et al., 2004; Geng et al., 2016) \\
\hline Anions $\left(\mathrm{SO}_{4}{ }^{2-}\right)$ & NAM & 10 & VFT & (Geng et al., 2016) \\
\hline Cinacalcet & PAM/phenylalkylamine & $0.051 \mu \mathrm{M}^{\mathrm{a}}$ & TMD & (Miedlich et al., 2002; Petrel et al., 2004; Nemeth et al., 2004) \\
\hline Calindol & PAM/phenylalkylamine & $0.31 \mu \mathrm{M}^{\mathrm{a}}$ & TMD & Miedlich et al., 2002; Petrel et al., 2004) \\
\hline NPS R-568 & PAM/phenylalkylamine & $0.5 \mu \mathrm{M}^{\mathrm{a}}$ & TMD & (Miedlich et al., 2002; Petrel et al., 2004) \\
\hline NPS R-467 & PAM/phenylalkylamine & 0.01 & TMD & (Miedlich et al., 2002; Petrel et al., 2004) \\
\hline$\gamma$-Glu-Val-Gly & PAM/Peptide & $0.041 \mu \mathrm{M}^{\mathrm{a}}$ & - & (Ohsu et al., 2010) \\
\hline$\gamma$-Glu-Cys-Gly (Glutathione) & PAM/Peptide & $76.5 \mu \mathrm{M}^{\mathrm{a}}$ & VFT & (Ohsu et al., 2010; Wang et al., 2006 \\
\hline$\gamma$-Glu-Ala & PAM/Peptide & $3.65 \mu \mathrm{M}^{\mathrm{a}}$ & ND & (Wang et al., 2006; Ohsu et al., 2010) \\
\hline$\gamma-$ Glu-Val & PAM/Peptide & $1.34 \mu \mathrm{M}^{\mathrm{a}}$ & ND & (Wang et al., 2006; Ohsu et al., 2010) \\
\hline$\gamma$-Glu-Cys & PAM/Peptide & $0.45 \mu \mathrm{M}^{\mathrm{a}}$ & VFT & (Ohsu et al., 2010; Wang et al., 2006) \\
\hline$\gamma$-Glu- $\alpha$-aminobutyryl-Gly (Opthalmic acid) & PAM/Peptide & $0.018 \mu \mathrm{M}^{\mathrm{a}}$ & ND & (Ohsu et al., 2010) \\
\hline NPS2143 & NAM & $0.0003(\mathrm{IC} 50)$ & TMD & (Gowen et al., 2000; Petrel et al., 2004) \\
\hline Calhex 231 & Mixed PAM/NAM & $0.1-1 \mu \mathrm{M}$ (PAM); 3-10 $\mu \mathrm{M}$ (NAM) & TMD & (Petrel et al., 2003; Petrel et al., 2004; Gregory et al., 2018) \\
\hline
\end{tabular}

Where VFT, venus flytrap domain; TMD, transmembrane domain; ND, not determined.

ashows EC50 value. 
As positive allosteric modulators, $\gamma$ glutamyl peptides including glutathione ( $\gamma$ Glu-Cys-Gly) and its analogs (Table 8) are predicted to have overlapping binding sites with L-amino acids in the VFT region (Wang et al., 2006; Ohsu et al., 2010; Broadhead et al., 2011). Kokumi peptides that activate CaSR resemble amino acids in having free $\alpha$-amino and free $\alpha$-carboxylate groups because they contain both amide bond formation between the $\gamma$-carboxylate group of L-glutamate and the $\alpha$-amino group of its neighboring Cys residue. However, compared to amino acids, glutathione analogs have much larger side chains and are more potent activators of CaSR (Wang et al., 2006). Nonetheless, the free sulfhydryl is not required for CaSR activation (Ohsu et al., 2010; Maruyama et al., 2012).

The crystal structure of ECD enables mapping of the GSH binding site and investigation into how GSH binding works in synergy with $\mathrm{Ca}^{2+}$ to modulate the kokumi sensation. NPS2143, the sole kokumi NAM identified to date has been reported to inhibit kokumi taste sensation to GSH and its analogs which provides an opportunity to screen for novel kokumi enhancing molecules in a cell-based assay.

\section{Synthetic Drugs as Allosteric Ligands of Calcium-Sensing Receptor}

Because of its pathophysiological importance, various synthetic PAMs and NAMs of CaSR have been identified and are in clinical use. The allosteric modulation of CaSR by synthetic drugs has been recently reviewed (Hannan et al., 2016; ChavezAbiega et al., 2020; Leach et al., 2020). Since the 1990's the term calcimimetics and calcilytics, have been used for drugs that mimic or antagonize the effect of extracellular $\mathrm{Ca}^{2+}$ on CaSR activity, respectively. Pharmacologically, a calcimimetic activates the CaSR and includes agonists (type I) and allosteric ligands (type II). Most type I calcimimetics are either inorganic or organic polycations (e.g., $\mathrm{Mg}^{2+}, \mathrm{Gd}^{3+}$, neomycin), whereas type II calcimimetics are small naturally occurring molecules (aromatic amino acids or GSH) or synthetic drugs and peptides (NPS R-568, cinacalcet). Type II calcimimetics (like aromatic amino acids) bind in the ECD while others (e.g., NPS R-568, NPS R-467) bind in the TMD of the CaSR. Calcilytics are thus small organic molecules that appear to act as NAMs and bind in the TMD of the receptor (Widler, 2011; Nemeth, 2013).

Homology modeling and mutational studies show that both PAMs and NAMs have overlapping but non-identical binding sites in TMD and can partially allosterically modulate CaSR activity in the complete absence of the ECD, but their potencies vary among structurally different compounds (Collins et al., 1998; Ma et al., 2011) (Table 8). Several residues reportedly critical for allosteric modulation, $\mathrm{W} 818^{6.48}, \mathrm{~F} 821^{6.51}$ (TMD6) and E837 ${ }^{7.39}$, I841 ${ }^{7.43}$ (TMD7), R680 ${ }^{3.28}, \mathrm{~F} 684^{3.32}, \mathrm{~F} 688^{3.36}$ (TMD3) impair calcimimetic and calcilytic induced CaSR signaling (Miedlich et al., 2004; Petrel et al., 2004; Leach et al., 2016). Nevertheless, subtle differences in ligand-receptor interactions drive negative vs. positive modulation of CaSR signaling, by NPS2143 or cinacalcet and NPSR-568, respectively (Miedlich et al., 2004; Leach et al., 2016; Keller et al., 2018). The details of CaSR allosteric modulation by synthetic drugs is out of the scope of the current review, for a comprehensive explanation refer to these studies (Chaves-López et al., 2014; Hannan et al., 2016; Leach et al., 2020).

\section{CONCLUSION}

Taste GPCR research has advanced rapidly over the past two decades providing a more thorough understanding of receptor molecular pharmacology and signal transduction pathways. With the exception of the kokumi receptor ECD, high-resolution crystal structures for any taste receptor would be a major step toward designing novel and potent surrogate taste receptor ligands and selective antagonists. This has been a challenge due to low taste GPCR functional heterologous expression, appropriate post-translational modifications, high conformational flexibility, and low detergent stability. However, significant advancements in structural biology technologies of serial femtosecond crystallography using $\mathrm{X}$-ray free-electron lasers and high-resolution cryo-electron microscopy provide promising tools for understanding conformational dynamics and visualizing the process of receptor activation with high spatial and temporal resolution. The physiological relevance of taste GPCRs will be further advanced through in vivo studies to help provide information on potential synergies in taste signal transduction mechanisms particularly among bitter, umami, sweet and kokumi receptors.

\section{AUTHOR CONTRIBUTIONS}

RA wrote the manuscript and prepared the figures and tables; JD contributed to writing and reviewing the manuscript.

\section{FUNDING}

This work was supported by an Endeavour Research Programme grant entitled "Accelerated evolution: A step change in food fermentation" (C10X1707) from the Ministry of Business Innovation \& Employment, New Zealand.

\section{ACKNOWLEDGMENTS}

We thank M. McCann and A. Heiser for critical appraisal of the manuscript.

\section{SUPPLEMENTARY MATERIAL}

The Supplementary Material for this article can be found online at: https://www.frontiersin.org/articles/10.3389/fphar.2020.587664/ full\#supplementary-material 


\section{REFERENCES}

Abaffy, T., Trubey, K. R., and Chaudhari, N. (2003). Adenylyl cyclase expression and modulation of cAMP in rat taste cells. Am. J. Physiol. Cell Physiol. 284 (6), C1420-C1428. doi:10.1152/ajpcell.00556.2002

Adler, E., Hoon, M. A., Mueller, K. L., Chandrashekar, J., Ryba, N. J., and Zuker, C. S. (2000). A novel family of mammalian taste receptors. Cell 100 (6), 693-702. doi:10.1016/S0092-8674(00)80705-9

Ahmad, R., Wojciech, S., and Jockers, R. (2015). Hunting for the function of orphan GPCRs - beyond the search for the endogenous ligand. Br. J. Pharmacol. 172 (13), 3212-3228. doi:10.1111/bph.12942

Alshehri, S. M., Park, J. B., Alsulays, B. B., Tiwari, R. V., Almutairy, B., Alshetaili, A. S., et al. (2015). Mefenamic acid taste-masked oral disintegrating tablets with enhanced solubility via molecular interaction produced by hot melt extrusion technology. J. Drug Deliv. Sci. Technol. 27, 18-27. doi:10.1016/j.jddst.2015.03.003

Avenet, P., Hofmann, F., and Lindemann, B. (1988). Transduction in taste receptor cells requires cAMP-dependent protein kinase. Nature 331 (6154), 351-354. doi:10.1038/331351a0.

Ayenew, Z., Puri, V., Kumar, L., and Bansal, A. K. (2009). Trends in pharmaceutical taste masking technologies: a patent review. Rec. Pat. Drug Deliv. Form. 3, 26-39. doi:10.2174/187221109787158364

Bai, M., Trivedi, S., and Brown, E. M. (1998). Dimerization of the extracellular calcium-sensing receptor (CaR) on the cell surface of CaR-transfected HEK293 cells. J. Biol. Chem. 273 (36), 23605-23610. doi:10.1074/jbc.273.36.23605

Ballesteros, J., and Weinstein, H. (1995). "[19] Integrated methods for the construction of three-dimensional models and computational probing of structure-function relations in G protein-coupled receptors,". Methods Neurosci. 25, 366-428.

Bartel, D. L., Sullivan, S. L., Lavoie, E. G., Sévigny, J., and Finger, T. E. (2006). Nucleoside triphosphate diphosphohydrolase-2 is the ecto-ATPase of type I cells in taste buds. J. Comp. Neurol. 497, 1-12. doi:10.1002/cne.20954

Behrens, M., Brockhoff, A., Batram, C., Kuhn, C., Appendino, G., and Meyerhof, W. (2009). The human bitter taste receptor hTAS2R50 is activated by the two natural bitter terpenoids andrographolide and amarogentin. J. Agric. Food Chem. 57 (21), 9860-9866. doi:10.1021/jf9014334

Behrens, M., Brockhoff, A., Kuhn, C., Bufe, B., Winnig, M., and Meyerhof, W. (2004). The human taste receptor hTAS2R14 responds to a variety of different bitter compounds. Biochem. Biophys. Res. Commun. 319, 479-485. doi:10.1016/ j.bbrc.2004.05.019

Behrens, M., and Meyerhof, W. (2009). Mammalian bitter taste perception. Results Probl. Cell Differ. 47, 203-220. doi:10.1007/400_2008_5

Behrens, M., and Meyerhof, W. (2011). Gustatory and extragustatory functions of mammalian taste receptors. Physiol. Behav. 105 (1), 4-13. doi:10.1016/j. physbeh.2011.02.010

Behrens, M., and Meyerhof, W. (2013). Bitter taste receptor research comes of age: from characterization to modulation of TAS2Rs. Semin. Cell Dev. Biol. 24, 215-221. doi:10.1016/j.semcdb.2012.08.006

Behrens, M., and Meyerhof, W. (2018). Vertebrate bitter taste receptors: keys for survival in changing environments. J. Agric. Food Chem. 66 (10), 2204-2213. doi:10.1021/acs.jafc.6b04835

Behrens, M., Redel, U., Blank, K., and Meyerhof, W. (2019). The human bitter taste receptor TAS2R7 facilitates the detection of bitter salts. Biochem. Biophys. Res. Commun. 512, 877-881. doi:10.1016/j.bbrc.2019.03.139

Biarnes, X., Marchiori, A., Giorgetti, A., Lanzara, C., Gasparini, P., Carloni, P., et al. (2010). Insights into the binding of phenyltiocarbamide (PTC) agonist to its target human TAS2R38 bitter receptor. PLoS One 5 (8), e12394. doi:10.1371/ journal.pone.0012394

Billington, C. K., and Penn, R. B. (2003). Signaling and regulation of G protein-coupled receptors in airway smooth muscle. Respir. Res. 4, 2. doi:10.1186/1465-9921-4-2

Born, S., Levit, A., Niv, M. Y., Meyerhof, W., and Behrens, M. (2013). The human bitter taste receptor TAS2R10 is tailored to accommodate numerous diverse ligands. J. Neurosci. 33 (1), 201-213. doi:10.1523/JNEUROSCI.3248-12.2013

Breitwieser, G. E. (2006). Calcium sensing receptors and calcium oscillations: calcium as a first messenger. Curr. Top. Dev. Biol. 73, 85-114. doi:10.1016/ S0070-2153(05)73003-9

Broadhead, G. K., Mun, H. C., Avlani, V. A., Jourdon, O., Church, W. B., Christopoulos, A., et al. (2011). Allosteric modulation of the calciumsensing receptor by gamma-glutamyl peptides: inhibition of PTH secretion, suppression of intracellular cAMP levels, and a common mechanism of action with L-amino acids. J. Biol. Chem. 286 (11), 8786-8797. doi:10.1074/jbc.M110.149724

Brockhoff, A., Behrens, M., Massarotti, A., Appendino, G., and Meyerhof, W. (2007). Broad tuning of the human bitter taste receptor hTAS2R46 to various sesquiterpene lactones, clerodane and labdane diterpenoids, strychnine, and denatonium. J. Agric. Food Chem. 55 (15), 6236-6243. doi:10.1021/jf070503p

Brockhoff, A., Behrens, M., Niv, M. Y., and Meyerhof, W. (2010). Structural requirements of bitter taste receptor activation. Proc. Natl. Acad. Sci. U.S.A. 107 (24), 11110-11115. doi:10.1073/pnas.0913862107

Brockhoff, A., Behrens, M., Roudnitzky, N., Appendino, G., Avonto, C., and Meyerhof, W. (2011). Receptor agonism and antagonism of dietary bitter compounds. J. Neurosci. 31 (41), 14775-14782. doi:10.1523/JNEUROSCI.2923-11.2011

Brown, E. M. (2007). Clinical lessons from the calcium-sensing receptor. Nat. Clin. Pract. Endocrinol. Metabol. 3 (2), 122-133. doi:10.1038/ncpendmet0388.

Brown, E. M., Gamba, G., Riccardi, D., Lombardi, M., Butters, R., Kifor, O., et al. (1993). Cloning and characterization of an extracellular $\mathrm{Ca}(2+)$-sensing receptor from bovine parathyroid. Nature 366 (6455), 575-580. doi:10.1038/366575a0

Brown, E. M., Katz, C., Butters, R., and Kifor, O. (1991). Polyarginine, polylysine, and protamine mimic the effects of high extracellular calcium concentrations on dispersed bovine parathyroid cells. J. Bone Miner. Res. 6, 1217-1225. doi:10. 1002/jbmr.5650061112

Brown, E. M., and MacLeod, R. J. (2001). Extracellular calcium sensing and extracellular calcium signaling. Physiol. Rev. 81 (1), 239-297. doi:10.1152/ physrev.2001.81.1.239

Brown, E. M. (2013). Role of the calcium-sensing receptor in extracellular calcium homeostasis. Best Pract. Res. Clin. Endocrinol. Metabol. 27 (3), 333-343. doi:10. 1016/j.beem.2013.02.006

Brown, H. B., Lewis, L. A., and Page, I. H. (1975). Effects of clofibrate and a fatmodified diet on serum lipids. Clin. Pharmacol. Ther. 17 (2), 171-178. doi:10. $1002 /$ cpt1975172171

Bufe, B., Hofmann, T., Krautwurst, D., Raguse, J. D., and Meyerhof, W. (2002). The human TAS2R16 receptor mediates bitter taste in response to betaglucopyranosides. Nat. Genet. 32, 397-401. doi:10.1038/ng1014

Burdock, G. A. (2005). Fenaroli's handbook of flavor ingredients. 5th Edn, Florida: CRC Press.

Bystrova, M. F., Romanov, R. A., Rogachevskaja, O. A., Churbanov, G. D., and Kolesnikov, S. S. (2010). Functional expression of the extracellular-Ca2+-sensing receptor in mouse taste cells. J. Cell Sci. 123 (Pt 6), 972-982. doi:10.1242/jcs.061879

Caicedo, A., and Roper, S. D. (2001). Taste receptor cells that discriminate between bitter stimuli. Science 291 (5508), 1557-1560. doi:10.1126/science.291.5508.1557

Centeno, P. P., Herberger, A., Mun, H. C., Tu, C., Nemeth, E. F., Chang, W., et al. (2019). Phosphate acts directly on the calcium-sensing receptor to stimulate parathyroid hormone secretion. Nat. Commun. 10 (1), 4693. doi:10.1038/ s41467-019-12399-9

Chalmers, D. T., and Behan, D. P. (2002). The use of constitutively active GPCRs in drug discovery and functional genomics. Nat. Rev. Drug Discov. 1 (8), 599-608. doi:10.1038/nrd872

Chandrashekar, J., Hoon, M. A., Ryba, N. J., and Zuker, C. S. (2006). The receptors and cells for mammalian taste. Nature 444 (7117), 288-294. doi:10.1038/nature05401

Chandrashekar, J., Mueller, K. L., Hoon, M. A., Adler, E., Feng, L., Guo, W., et al. (2000). T2Rs function as bitter taste receptors. Cell 100 (6), 703-711. doi:10. 1016/S0092-8674(00)80706-0

Chaudhari, N., Landin, A. M., and Roper, S. D. (2000). A metabotropic glutamate receptor variant functions as a taste receptor. Nat. Neurosci. 3 (2), 113-119. doi: $10.1038 / 72053$

Chaudhari, N., and Roper, S. D. (2010). The cell biology of taste. J. Cell Biol. 190 (3), 285-296. doi:10.1083/jcb.201003144

Chaves-López, C., Serio, A., Paparella, A., Martuscelli, M., Corsetti, A., Tofalo, R., et al. (2014). Impact of microbial cultures on proteolysis and release of bioactive peptides in fermented milk. Food Microbiol. 42, 117-121. doi:10.1016/j.fm. 2014.03.005

Chavez-Abiega, S., Mos, I., Centeno, P. P., Elajnaf, T., Schlattl, W., Ward, D. T., et al. (2020). Sensing extracellular calcium - an insight into the structure and function of the calcium-sensing receptor (CaSR). Adv. Exp. Med. Biol. 1131, 1031-1063. doi:10.1007/978-3-030-12457-1_41

Cheron, J. B., Soohoo, A., Wang, Y., Golebiowski, J., Antonczak, S., Jiang, P., et al. (2019). Corrigendum: conserved residues control the T1R3-specific allosteric signaling pathway of the mammalian sweet-taste receptor. Chem. Senses 44 (8), 649-650. doi:10.1093/chemse/bjz038 
Clapp, T. R., Stone, L. M., Margolskee, R. F., and Kinnamon, S. C. (2001). Immunocytochemical evidence for co-expression of Type III IP3 receptor with signaling components of bitter taste transduction. BMC Neurosci. 2, 6. doi:10.1186/1471-2202-2-6

Clark, A. A., Liggett, S. B., and Munger, S. D. (2012). Extraoral bitter taste receptors as mediators of off-target drug effects. FASEB J. 26 (12), 4827-4831. doi:10. 1096/fj.12-215087

Collins, M. T., Skarulis, M. C., Bilezikian, J. P., Silverberg, S. J., Spiegel, A. M., and Marx, S. J. (1998). Treatment of hypercalcemia secondary to parathyroid carcinoma with a novel calcimimetic agent. J. Clin. Endocrinol. Metab. 83 (4), 1083-1088. doi:10.1210/jcem.83.4.4726

Conigrave, A. D., and Hampson, D. R. (2006). Broad-spectrum L-amino acid sensing by class $3 \mathrm{G}$-protein-coupled receptors. Trends Endocrinol Metab 17 (10), 398-407. doi:10.1016/j.tem.2006.10.012

Conigrave, A. D., Quinn, S. J., and Brown, E. M. (2000). L-amino acid sensing by the extracellular Ca2+-sensing receptor. Proc. Natl. Acad. Sci. U.S.A. 97 (9), 4814-4819. doi:10.1073/pnas.97.9.4814

Conigrave, A. D., and Ward, D. T. (2013). Calcium-sensing receptor (CaSR): pharmacological properties and signaling pathways. Best Pract. Res. Clin. Endocrinol. Metabol. 27 (3), 315-331. doi:10.1016/j.beem.2013.05.010

Cowart, B. J., Yokomukai, Y., and Beauchamp, G. K. (1994). Bitter taste in aging: compound-specific decline in sensitivity. Physiol. Behav. 56, 1237-1241. doi:10. 1016/0031-9384(94)90371-9

Dai, W., You, Z., Zhou, H., Zhang, J., and Hu, Y. (2011). Structure-function relationships of the human bitter taste receptor hTAS2R1: insights from molecular modeling studies. J. Recept. Signal Transduct. Res. 31 (3), 229-240. doi:10.3109/10799893.2011.578141

Damak, S., Rong, M., Yasumatsu, K., Kokrashvili, Z., Pérez, C. A., Shigemura, N., et al. (2006). Trpm 5 null mice respond to bitter, sweet, and umami compounds. Chem. Senses 31 (3), 253-264. doi:10.1093/chemse/bjj027

Damak, S., Rong, M., Yasumatsu, K., Kokrashvili, Z., Varadarajan, V., Zou, S., et al. (2003). Detection of sweet and umami taste in the absence of taste receptor T1r3. Science 301 (5634), 850-853. doi:10.1126/science.1087155

DeFazio, R. A., Dvoryanchikov, G., Maruyama, Y., Kim, J. W., Pereira, E., Roper, S. D., et al. (2006). Separate populations of receptor cells and presynaptic cells in mouse taste buds. J. Neurosci. 26, 3971-3980. doi:10.1523/JNEUROSCI.051506.2006

Depoortere, I. (2014). Taste receptors of the gut: emerging roles in health and disease. Gut 63 (1), 179-190. doi:10.1136/gutjnl-2013-305112

Devillier, P., Naline, E., and Grassin-Delyle, S. (2015). The pharmacology of bitter taste receptors and their role in human airways. Pharmacol. Ther. 155, 11-21. doi:10.1016/j.pharmthera.2015.08.001

Di Pizio, A., Levit, A., Slutzki, M., Behrens, M., Karaman, R., and Niv, M. Y. (2016). Comparing Class A GPCRs to bitter taste receptors: structural motifs, ligand interactions and agonist-to-antagonist ratios. Methods Cell Biol. 132, 401-427. doi:10.1016/bs.mcb.2015.10.005

Di Pizio, A., and Niv, M. Y. (2015). Promiscuity and selectivity of bitter molecules and their receptors. Bioorg. Med. Chem. 23 (14), 4082-4091. doi:10.1016/j.bmc. 2015.04.025

Di Pizio, A., Waterloo, L. A. W., Brox, R., Lober, S., Weikert, D., Behrens, M., et al. (2020). Rational design of agonists for bitter taste receptor TAS2R14: from modeling to bench and back. Cell. Mol. Life Sci. 77 (3), 531-542. doi:10.1007/ s00018-019-03194-2

Dotson, C. D., Zhang, L., Xu, H., Shin, Y. K., Vigues, S., Ott, S. H., et al. (2008). Bitter taste receptors influence glucose homeostasis. PLoS One 3, e3974. doi:10. 1371/journal.pone.0003974

Drewnowski, A., and Gomez-Carneros, C. (2000). Bitter taste, phytonutrients, and the consumer: a review. Am. J. Clin. Nutr. 72, 1424-1435. doi:10.1093/ajcn/72.6. 1424

DuBois, G. E. (1995). "New insights on the coding of the sweet taste message in chemical structure, in Firmenich jubilee symposium 1895-1995 olfaction and taste: a century for the senses, Carol Stream, IL: Geneva, Switzerland: Allured Publishing Corp 32-95.

DuBois, G. E. (2016). Molecular mechanism of sweetness sensation. Physiol. Behav. 164 (Pt B), 453-463. doi:10.1016/j.physbeh.2016.03.015

Dunkel, A., Hofmann, T., and Di Pizio, A. (2020). In silico investigation of bitter hop-derived compounds and their cognate bitter taste receptors. J. Agric. Food Chem. 68, 38. doi:10.1021/acs.jafc.9b07863.
Dunkel, A., Koster, J., and Hofmann, T. (2007). Molecular and sensory characterization of gamma-glutamyl peptides as key contributors to the kokumi taste of edible beans (Phaseolus vulgaris L.). J. Agric. Food Chem. 55 (16), 6712-6719. doi:10.1021/jf071276u

Dutta Banik, D., Martin, L. E., Freichel, M., Torregrossa, A.-M., and Medler, K. F. (2018). TRPM4 and TRPM5 are both required for normal signaling in taste receptor cells. Proc. Natl. Acad. Sci. U.S.A. 115 (4), E772. doi:10.1073/pnas. 1718802115

Dvoryanchikov, G., Sinclair, M. S., Perea-Martinez, I., Wang, T., and Chaudhari, N. (2009). Inward rectifier channel, ROMK, is localized to the apical tips of gliallike cells in mouse taste buds. J. Comp. Neurol. 517 (1), 1-14. doi:10.1002/cne. 22152

Eddy, M. C., Eschle, B. K., Peterson, D., Lauras, N., Margolskee, R. F., and Delay, E. R. (2012). A conditioned aversion study of sucrose and SC45647 taste in TRPM5 knockout mice. Chem. Senses 37 (5), 391-401. doi:10.1093/chemse/ bjr093

Finger, T. E., Danilova, V., Barrows, J., Bartel, D. L., Vigers, A. J., Stone, L., et al. (2005). ATP signaling is crucial for communication from taste buds to gustatory nerves. Science 310 (5753), 1495-1499. doi:10.1126/science.1118435

Fletcher, J. N., Kinghorn, A. D., Slack, J. P., McCluskey, T. S., Odley, A., and Jia, Z. (2011). In vitro evaluation of flavonoids from Eriodictyon californicum for antagonist activity against the bitterness receptor hTAS2R31. J. Agric. Food Chem. 59, 13117-13121. doi:10.1021/jf204359q

Floriano, W. B., Hall, S., Vaidehi, N., Kim, U., Drayna, D., and Goddard, W. A., 3rd (2006). Modeling the human PTC bitter-taste receptor interactions with bitter tastants. J. Mol. Model. 12 (6), 931-941. doi:10.1007/s00894-0060102-6

Fredriksson, R., Lagerstrom, M. C., Lundin, L. G., and Schioth, H. B. (2003). The G-protein-coupled receptors in the human genome form five main families. Phylogenetic analysis, paralogon groups, and fingerprints. Mol. Pharmacol. 63 (6), 1256-1272. doi:10.1124/mol.63.6.1256

Fuhr, U., Klittich, K., and Staib, A. H. (1993). Inhibitory effect of grapefruit juice and its bitter principal, naringenin, on CYP1A2 dependent metabolism of caffeine in man. Br. J. Clin. Pharmacol. 35, 431-436. doi:10.1111/j.1365-2125. 1993.tb04162.x

Gama, L., and Breitwieser, G. E. (1998). A carboxyl-terminal domain controls the cooperativity for extracellular $\mathrm{Ca} 2+$ activation of the human calcium sensing receptor. A study with receptor-green fluorescent protein fusions. J. Biol. Chem. 273 (45), 29712-29718. doi:10.1074/jbc.273.45.29712

Geng, Y., Mosyak, L., Kurinov, I., Zuo, H., Sturchler, E., Cheng, T. C., et al. (2016). Structural mechanism of ligand activation in human calcium-sensing receptor. Elife 5, 13662. doi:10.7554/eLife.13662

Ghanavatian, P., Khalifeh, K., and Jafarian, V. (2016). Structural features and activity of Brazzein and its mutants upon substitution of a surfaced exposed alanine. Biochimie 131, 20-28. doi:10.1016/j.biochi.2016.09.006

Glendinning, J. I. (1994). Is the bitter rejection response always adaptive? Physiol. Behav. 56, 1217-1227. doi:10.1016/0031-9384(94)90369-7

Gowen, M., Stroup, G. B., Dodds, R. A., James, I. E., Votta, B. J., Smith, B. R., et al. (2000). Antagonizing the parathyroid calcium receptor stimulates parathyroid hormone secretion and bone formation in osteopenic rats. J. Clin. Invest. 105, 1595-1604. doi:10.1172/JCI9038

Greene, T. A., Alarcon, S., Thomas, A., Berdougo, E., Doranz, B. J., Breslin, P. A., et al. (2011). Probenecid inhibits the human bitter taste receptor TAS2R16 and suppresses bitter perception of salicin. PLoS One 6 (5), e20123. doi:10.1371/ journal.pone.0020123

Gregory, K. J., Kufareva, I., Keller, A. N., et al. (2018). Dual action calcium-sensing receptor modulator unmasks novel mode-switching mechanism. ACS Pharmacol Transl Sci. 1, 96-109. doi:10.1021/acsptsci.8b00021

Gregory, K. J., Nguyen, E. D., Reiff, S. D., Squire, E. F., Stauffer, S. R., Lindsley, C. W., et al. (2013). Probing the metabotropic glutamate receptor 5 (mGlus) positive allosteric modulator (PAM) binding pocket: discovery of point mutations that engender a "molecular switch" in PAM pharmacology. Mol. Pharmacol. 83 (5), 991-1006. doi:10.1124/mol.112.083949

Guinard, J. X., Hong, D. Y., Zoumas-Morse, C., Budwig, C., and Russell, G. F. (1994). Chemoreception and perception of the bitterness of isohumulones. Physiol. Behav. 56, 1257-1263. doi:10.1016/0031-9384(94)90374-3

Hamor, G. H. (1961). Correlation of chemical structure and taste in the saccharin series. Science 134, 1416-1417. doi:10.1126/science.134.3488.1416 
Hannan, F. M., Babinsky, V. N., and Thakker, R. V. (2016). Disorders of the calcium-sensing receptor and partner proteins: insights into the molecular basis of calcium homeostasis. J. Mol. Endocrinol. 57 (3), R127-R142. doi:10.1530/ jme-16-0124

He, W., Yasumatsu, K., Varadarajan, V., Yamada, A., Lem, J., Ninomiya, Y., et al. (2004). Umami taste responses are mediated by alpha-transducin and alpha-gustducin. J. Neurosci. 24 (35), 7674-7680. doi:10.1523/JNEUROSCI.2441-04.2004

Hellfritsch, C., Brockhoff, A., Stahler, F., Meyerhof, W., and Hofmann, T. (2012). Human psychometric and taste receptor responses to steviol glycosides. J. Agric. Food Chem. 60, 6782-6793. doi:10.1021/jf301297n

Hendy, G. N., Canaff, L., and Cole, D. E. (2013). The CASR gene: alternative splicing and transcriptional control, and calcium-sensing receptor (CaSR) protein: structure and ligand binding sites. Best Pract. Res. Clin. Endocrinol. Metabol. 27 (3), 285-301. doi:10.1016/j.beem.2013.02.009

Hendy, G. N., Guarnieri, V., and Canaff, L. (2009). Calcium-sensing receptor and associated diseases. Prog Mol Biol Transl Sci 89, 31-95. doi:10.1016/s18771173(09)89003-0

Hisatsune, C., Yasumatsu, K., Takahashi-Iwanaga, H., Ogawa, N., Kuroda, Y., Yoshida, R., et al. (2007). Abnormal taste perception in mice lacking the type 3 inositol 1,4,5-trisphosphate receptor. J. Biol. Chem. 282 (51), 37225-37231. doi:10.1074/jbc.M705641200

Hoon, M. A., Adler, E., Lindemeier, J., Battey, J. F., Ryba, N. J., and Zuker, C. S. (1999). Putative mammalian taste receptors: a class of taste-specific GPCRs with distinct topographic selectivity. Cell 96 (4), 541-551. doi:10.1016/S00928674(00)80658-3

Horn, F., Bettler, E., Oliveira, L., Campagne, F., Cohen, F. E., and Vriend, G. (2003). GPCRDB information system for G protein-coupled receptors. Nucleic Acids Res. 31 (1), 294-297. doi:10.1093/nar/gkg103

Huang, L., Shanker, Y. G., Dubauskaite, J., Zheng, J. Z., Yan, W., Rosenzweig, S., et al. (1999). Ggamma13 colocalizes with gustducin in taste receptor cells and mediates IP3 responses to bitter denatonium. Nat. Neurosci. 2 (12), 1055-1062. doi:10.1038/15981

Huang, Y., Niwa, J., Sobue, G., and Breitwieser, G. E. (2006). Calcium-sensing receptor ubiquitination and degradation mediated by the E3 ubiquitin ligase dorfin. J. Biol. Chem. 281 (17), 11610-11617. doi:10.1074/jbc.M513552200

Huang, Y., Zhou, Y., Castiblanco, A., Yang, W., Brown, E. M., and Yang, J. J. (2009). Multiple $\mathrm{Ca}(2+)$-binding sites in the extracellular domain of the $\mathrm{Ca}(2+)$-sensing receptor corresponding to cooperative $\mathrm{Ca}(2+)$ response. Biochemistry 48 (2), 388-398. doi:10.1021/bi8014604

Huang, Y., Zhou, Y., Yang, W., Butters, R., Lee, H. W., Li, S., et al. (2007). Identification and dissection of $\mathrm{Ca}(2+)$-binding sites in the extracellular domain of $\mathrm{Ca}(2+)$-sensing receptor. J. Biol. Chem. 282 (26), 19000-19010. doi:10.1074/ jbc.M701096200

Ide, N., Sato, E., Ohta, K., Masuda, T., and Kitabatake, N. (2009). Interactions of the sweet-tasting proteins thaumatin and lysozyme with the human sweet-taste receptor. J. Agric. Food Chem. 57, 5884-5890. doi:10.1021/jf803956f

Ikeda, K. (2002). New seasonings. Chem. Senses 27 (9), 847-849. doi:10.1093/ chemse/27.9.847

Imada, T., Misaka, T., Fujiwara, S., Okada, S., Fukuda, Y., and Abe, K. (2010). Amiloride reduces the sweet taste intensity by inhibiting the human sweet taste receptor. Biochem. Biophys. Res. Commun. 397, 220-225. doi:10.1016/j.bbrc. 2010.05.088

Intelmann, D., Batram, C., Kuhn, C., Haseleu, G., Meyerhof, W., and Hofmann, T. (2009). Three TAS2R bitter taste receptors mediate the psychophysical responses to bitter compounds of hops (Humulus lupulus L.) and beer. Chemosens. Percept. 2, 118-132. doi:10.1007/s12078-009-9049-1

Ishimaru, Y. (2009). Molecular mechanisms of taste transduction in vertebrates. Odontology 97 (1), 1-7. doi:10.1007/s10266-008-0095-y

Iwata, S., Yoshida, R., and Ninomiya, Y. (2014). Taste transductions in taste receptor cells: basic tastes and moreover. Curr. Pharmaceut. Des. 20 (16), 2684-2692. doi:10.2174/13816128113199990575

Jaggupilli, A., Howard, R., Aluko, R. E., and Chelikani, P. (2019). Advanced glycation end-products can activate or block bitter taste receptors. Nutrients 11, 1317. doi:10.3390/nu11061317

Jaggupilli, A., Howard, R., Upadhyaya, J. D., Bhullar, R. P., and Chelikani, P. (2016). Bitter taste receptors: novel insights into the biochemistry and pharmacology. Int. J. Biochem. Cell Biol. 77, 184-196. doi:10.1016/j.biocel. 2016.03.005
Jaggupilli, A., Singh, N., De Jesus, V. C., Gounni, M. S., Dhanaraj, P., and Chelikani, P. (2019). Chemosensory bitter taste receptors (T2Rs) are activated by multiple antibiotics. FASEB J. 33 (1), 501-517. doi:10.1096/fj.201800521RR

Jaggupilli, A., Singh, N., Jesus, V. C., Duan, K., and Chelikani, P. (2018). Characterization of the binding sites for bacterial acyl homoserine lactones (AHLs) on human bitter taste receptors (T2Rs). ACS Infect. Dis. 4 (7), 1146-1156. doi:10.1021/acsinfecdis.8b00094

Janssen, S., and Depoortere, I. (2013). Nutrient sensing in the gut: new roads to therapeutics? Trends Endocrinol Metab 24 (2), 92-100. doi:10.1016/j.tem.2012. 11.006

Jiang, P., Cui, M., Ji, Q., Snyder, L., Liu, Z., Benard, L., et al. (2005a). Molecular mechanisms of sweet receptor function. Chem. Senses 30 (Suppl. 1), i17-i18. doi:10.1093/chemse/bjh091

Jiang, P., Cui, M., Zhao, B., Liu, Z., Snyder, L. A., Benard, L. M., et al. (2005b). Lactisole interacts with the transmembrane domains of human T1R3 to inhibit sweet taste. J. Biol. Chem. 280 (15), 15238-15246. doi:10.1074/jbc.M414287200

Jiang, P., Cui, M., Zhao, B., Snyder, L. A., Benard, L. M., Osman, R., et al. (2005c). Identification of the cyclamate interaction site within the transmembrane domain of the human sweet taste receptor subunit T1R3. J. Biol. Chem. 280 (40), 34296-34305. doi:10.1074/jbc.M505255200

Jiang, P., Ji, Q., Liu, Z., Snyder, L. A., Benard, L. M., Margolskee, R. F., and Max, M. (2004). The cysteine-rich region of T1R3 determines responses to intensely sweet proteins. J. Biol. Chem. 279 (43), 45068-45075. https://doi.org/10.1074/ jbc.M406779200

Jingami, H., Nakanishi, S., and Morikawa, K. (2003). Structure of the metabotropic glutamate receptor. Curr. Opin. Neurobiol. 13 (3), 271-278. doi:10.1016/s09594388(03)00067-9

Jones, K. A., Borowsky, B., Tamm, J. A., Craig, D. A., Durkin, M. M., Dai, M., et al. (1998). GABA(B) receptors function as a heteromeric assembly of the subunits GABA(B)R1 and GABA(B)R2. Nature 396 (6712), 674-679. doi:10.1038/25348

Katz, C. L., Butters, R. R., Chen, C. J., and Brown, E. M. (1992). Structure-function relationships for the effects of various aminoglycoside antibiotics on dispersed bovine parathyroid cells. Endocrinology 131, 903-910. doi:10.1210/endo.131.2.1322287

Kaupmann, K., Malitschek, B., Schuler, V., Heid, J., Froestl, W., Beck, P., et al. (1998). GABA(B)-receptor subtypes assemble into functional heteromeric complexes. Nature 396 (6712), 683-687. doi:10.1038/25360

Keller, A. N., Kufareva, I., Josephs, T. M., Diao, J., Mai, V. T., Conigrave, A. D., et al. (2018). Identification of global and ligand-specific calcium sensing receptor activation mechanisms. Mol. Pharmacol. 93 (6), 619-630. doi:10.1124/mol.118. 112086

Kelly, P., Casey, P. J., and Meigs, T. E. (2007). Biologic functions of the G12 subfamily of heterotrimeric G Proteins: growth, migration, and metastasis. Biochemistry 46 (23), 6677-6687. doi:10.1021/bi700235f

Kim, M. J., Son, H. J., Kim, Y., Misaka, T., and Rhyu, M. R. (2015). Umami-bitter interactions: the suppression of bitterness by umami peptides via human bitter taste receptor. Biochem. Biophys. Res. Commun. 456 (2), 586-590. doi:10.1016/j. bbrc.2014.11.114

Kim, S. K., Chen, Y., Abrol, R., Goddard, W. A., 3rd, and Guthrie, B. (2017). Activation mechanism of the $\mathrm{G}$ protein-coupled sweet receptor heterodimer with sweeteners and allosteric agonists. Proc. Natl. Acad. Sci. U.S.A. 114 (10), 2568-2573. doi:10.1073/pnas.1700001114

Kinnamon, S. C. (2009). Umami taste transduction mechanisms. Am. J. Clin. Nutr. 90 (3), 753S-755S. doi:10.3945/ajcn.2009.27462K

Kochem, M., and Breslin, P. A. (2017). Lipid-lowering pharmaceutical clofibrate inhibits human sweet taste. Chem. Senses 42, 79-83. doi:10.1093/chemse/bjw104

Kohl, S., Behrens, M., Dunkel, A., Hofmann, T., and Meyerhof, W. (2013). Amino acids and peptides activate at least five members of the human bitter taste receptor family. J. Agric. Food Chem. 61, 53-60. doi:10.1021/jf303146h

Koizumi, A., Nakajima, K., Asakura, T., Morita, Y., Ito, K., Shmizu-Ibuka, A., et al. (2007). Taste-modifying sweet protein, neoculin, is received at human T1R3 amino terminal domain. Biochem. Biophys. Res. Commun. 358, 585-589. doi:10. 1016/j.bbrc.2007.04.171

Kuhn, C., Bufe, B., Winnig, M., Hofmann, T., Frank, O., Behrens, M., et al. (2004). Bitter taste receptors for saccharin and acesulfame K. J. Neurosci. 24 (45), 10260-10265. doi:10.1523/JNEUROSCI.1225-04.2004

Kunishima, N., Shimada, Y., Tsuji, Y., Sato, T., Yamamoto, M., Kumasaka, T., et al. (2000). Structural basis of glutamate recognition by a dimeric metabotropic glutamate receptor. Nature 407 (6807), 971-977. doi:10.1038/35039564 
Kuroda, M., and Miyamura, N. (2015). Mechanism of the perception of "kokumi" substances and the sensory characteristics of the "kokumi" peptide, $\gamma$-Glu-ValGly. Flavour 4 (11), 1-3. doi:10.1186/2044-7248-4-11

Kusuhara, Y., Yoshida, R., Ohkuri, T., Yasumatsu, K., Voigt, A., Hübner, S., et al. (2013). Taste responses in mice lacking taste receptor subunit T1R1. J Physiol 591, 1967-1985. doi:10.1113/jphysiol.2012.236604

Lagerström, M. C., and Schiöth, H. B. (2008). Structural diversity of G proteincoupled receptors and significance for drug discovery. Nat. Rev. Drug Discov. 7 (4), 339-357. doi:10.1038/nrd2518

Lawton, D. M., Furness, D. N., Lindemann, B., and Hackney, C. M. (2000). Localization of the glutamate-aspartate transporter, GLAST, in rat taste buds. Eur. J. Neurosci. 12, 3163-3171. doi:10.1046/j.1460-9568.2000.00207.x

Le Neve, B., Foltz, M., Daniel, H., and Gouka, R. (2010). The steroid glycoside H.g.12 from Hoodia gordonii activates the human bitter receptor TAS2R14 and induces CCK release from HuTu-80 cells. Am. J. Physiol. Gastrointest. Liver Physiol. 299, G1368-G13675. doi:10.1152/ajpgi.00135.2010

Leach, K., and Gregory, K. J. (2017). Molecular insights into allosteric modulation of class C G protein-coupled receptors. Pharmacol. Res. 116, 105-118. doi:10. 1016/j.phrs.2016.12.006

Leach, K., Gregory, K. J., Kufareva, I., Khajehali, E., Cook, A. E., Abagyan, R., et al. (2016). Towards a structural understanding of allosteric drugs at the human calcium-sensing receptor. Cell Res. 26 (5), 574-592. doi:10.1038/cr.2016.36

Leach, K., Hannan, F. M., Josephs, T. M., Keller, A. N., Møller, T. C., Ward, D. T., et al. (2020). International union of basic and clinical pharmacology. CVIII. calcium-sensing receptor nomenclature, pharmacology, and function. Pharmacol. Rev. 72 (3), 558-604. doi:10.1124/pr.119.018531

Lee, H., Macpherson, L. J., Parada, C. A., Zuker, C. S., and Ryba, N. J. P. (2017). Rewiring the taste system. Nature 548 (7667), 330-333. doi:10.1038/ nature 23299

Levit, A., Nowak, S., Peters, M., Wiener, A., Meyerhof, W., Behrens, M., et al. (2014). The bitter pill: clinical drugs that activate the human bitter taste receptor TAS2R14. FASEB J 28, 1181-1197. doi:10.1096/fj.13-242594

Ley, J. P., Dessoy, M., Paetz, S., Blings, M., Hoffmann-Lücke, P., Reichelt, K. V., et al. (2012). Identification of enterodiol as a masker for caffeine bitterness by using a pharmacophore model based on structural analogues of homoeriodictyol. J. Agric. Food Chem. 60, 6303-6311. doi: $10.1021 / \mathrm{jf} 301335 \mathrm{z}$

Li, X., Staszewski, L., Xu, H., Durick, K., Zoller, M., and Adler, E. (2002). Human receptors for sweet and umami taste. Proc. Natl. Acad. Sci. U.S.A. 99 (7), 4692-4696. doi:10.1073/pnas.072090199

Liu, B., Ha, M., Meng, X. Y., Kaur, T., Khaleduzzaman, M., Zhang, Z., et al. (2011). Molecular mechanism of species-dependent sweet taste toward artificial sweeteners. J. Neurosci. 31 (30), 11070-11076. doi:10.1523/JNEUROSCI. 0791-11.2011

Liu, K., Jaggupilli, A., Premnath, D., and Chelikani, P. (2018). Plasticity of the ligand binding pocket in the bitter taste receptor T2R7. Biochim. Biophys. Acta Biomembr. 1860 (5), 991-999. doi:10.1016/j.bbamem.2018.01.014

Lopez Cascales, J. J., Oliveira Costa, S. D., de Groot, B. L., and Walters, D. E. (2010). Binding of glutamate to the umami receptor. Biophys. Chem. 152 (1-3), 139-144. doi:10.1016/j.bpc.2010.09.001

Lossow, K., Hubner, S., Roudnitzky, N., Slack, J. P., Pollastro, F., Behrens, M., et al. (2016). Comprehensive analysis of mouse bitter taste receptors reveals different molecular receptive ranges for orthologous receptors in mice and humans. J. Biol. Chem. 291, 15358-15377. doi:10.1074/jbc.M116.718544

Lundstrom, K. (2009). An overview on GPCRs and drug discovery: structure-based drug design and structural biology on GPCRs. Methods Mol. Biol. 552, 51-66. doi:10.1007/978-1-60327-317-6_4

Ma, J. N., Owens, M., Gustafsson, M., Jensen, J., Tabatabaei, A., Schmelzer, K., et al. (2011). Characterization of highly efficacious allosteric agonists of the human calcium-sensing receptor. J. Pharmacol. Exp. Therapeut. 337 (1), 275-284. doi:10.1124/jpet.110.178194

Ma, Z., Taruno, A., Ohmoto, M., Jyotaki, M., Lim, J. C., Miyazaki, H., et al. (2018). CALHM3 is essential for rapid ion channel-mediated purinergic neurotransmission of GPCR-mediated tastes. Neuron 98 (3), 547-561.e510. doi:10.1016/j.neuron.2018.03.043

Maehashi, K., Matano, M., Wang, H., Vo, L. A., Yamamoto, Y., and Huang, L. (2008). Bitter peptides activate hTAS2Rs, the human bitter receptors. Biochem. Biophys. Res. Commun. 365, 851-855. doi:10.1016/j.bbrc.2007.11.070
Magno, A. L., Ward, B. K., and Ratajczak, T. (2011). The calcium-sensing receptor: a molecular perspective. Endocr. Rev. 32 (1), 3-30. doi:10.1210/er. 2009-0043

Mahalapbutr, P., Darai, N., Panman, W., Opasmahakul, A., Kungwan, N., Hannongbua, S., et al. (2019). Atomistic mechanisms underlying the activation of the $\mathrm{G}$ protein-coupled sweet receptor heterodimer by sugar alcohol recognition. Sci. Rep. 9, 10205. doi:10.1038/s41598-019-46668-w

Maillet, E. L., Margolskee, R. F., and Mosinger, B. (2009). Phenoxy herbicides and fibrates potently inhibit the human chemosensory receptor subunit T1R3. J. Med. Chem. 52 (21), 6931-6935. doi:10.1021/jm900823s

Mamillapalli, R., VanHouten, J., Zawalich, W., and Wysolmerski, J. (2008). Switching of G-protein usage by the calcium-sensing receptor reverses its effect on parathyroid hormone-related protein secretion in normal versus malignant breast cells. J. Biol. Chem. 283 (36), 24435-24447. doi:10.1074/ jbc.M801738200

Mancuso, G., Borgonovo, G., Scaglioni, L., and Bassoli, A. (2015). Phytochemicals from Ruta graveolens activate TAS2R bitter taste receptors and TRP channels involved in gustation and nociception. Molecules 20, 18907-18922. doi:10.3390/ molecules201018907

Margolskee, R. F. (2002). Molecular mechanisms of bitter and sweet taste transduction. J. Biol. Chem. 277 (1), 1-4. doi:10.1074/jbc.R100054200

Maruyama, Y., Yasuda, R., Kuroda, M., and Eto, Y. (2012). Kokumi substances, enhancers of basic tastes, induce responses in calcium-sensing receptor expressing taste cells. PLoS One 7 (4), e34489. doi:10.1371/journal.pone. 0034489

Masuda, K., Koizumi, A., Nakajima, K., Tanaka, T., Abe, K., Misaka, T., et al. (2012). Characterization of the modes of binding between human sweet taste receptor and low-molecular-weight sweet compounds. PLoS One 7, e35380. doi:10.1371/journal.pone.0035380

Matsunami, H., Montmayeur, J. P., and Buck, L. B. (2000). A family of candidate taste receptors in human and mouse. Nature 404, 601-604. doi:10.1038/ 35007072

Mattes, R. D. (1994). Influences on acceptance of bitter foods and beverages. Physiol. Behav. 56, 1229-1236. doi:10.1016/0031-9384(94)90370-0

Max, M., Shanker, Y. G., Huang, L., Rong, M., Liu, Z., Campagne, F., et al. (2001). Tas1r3, encoding a new candidate taste receptor, is allelic to the sweet responsiveness locus Sac. Nat. Genet. 28 (1), 58-63. doi:10.1038/ng0501-58

McLaughlin, S. K., McKinnon, P. J., and Margolskee, R. F. (1992). Gustducin is a taste-cell-specific G protein closely related to the transducins. Nature 357 (6379), 563-569. doi:10.1038/357563a0

Meyerhof, W., Batram, C., Kuhn, C., Brockhoff, A., Chudoba, E., Bufe, B., et al. (2010). The molecular receptive ranges of human TAS2R bitter taste receptors. Chem. Senses 35 (2), 157-170. doi:10.1093/chemse/bjp092

Miedlich, S., Gama, L., and Breitwieser, G. E. (2002). Calcium sensing receptor activation by a calcimimetic suggests a link between cooperativity and intracellular calcium oscillations. J. Biol. Chem. 277, 49691-49699. doi:10. 1074/jbc.M205578200

Miedlich, S. U., Gama, L., Seuwen, K., Wolf, R. M., and Breitwieser, G. E. (2004). Homology modeling of the transmembrane domain of the human calcium sensing receptor and localization of an allosteric binding site. J. Biol. Chem. 279 (8), 7254-7263. doi:10.1074/jbc.M307191200

Miguet, L., Zhang, Z., and Grigorov, M. G. (2006). Computational studies of ligand-receptor interactions in bitter taste receptors. J. Recept. Signal Transduct. Res. 26 (5-6), 611-630. doi:10.1080/10799890600928210

Mouritsen, O. G., and Khandelia, H. (2012). Molecular mechanism of the allosteric enhancement of the umami taste sensation. FEBS J. 279 (17), 3112-3120. doi:10. 1111/j.1742-4658.2012.08690.x

Mueller, K. L., Hoon, M. A., Erlenbach, I., Chandrashekar, J., Zuker, C. S., and Ryba, N. J. (2005). The receptors and coding logic for bitter taste. Nature 434 (7030), 225-229. doi:10.1038/nature03352

Mun, H. C., Culverston, E. L., Franks, A. H., Collyer, C. A., Clifton-Bligh, R. J., and Conigrave, A. D. (2005). A double mutation in the extracellular Ca2+-sensing receptor's venus flytrap domain that selectively disables $\mathrm{L}$-amino acid sensing. J. Biol. Chem. 280 (32), 29067-29072. doi:10.1074/jbc.M500002200

Mun, H. C., Franks, A. H., Culverston, E. L., Krapcho, K., Nemeth, E. F., and Conigrave, A. D. (2004). The Venus Fly Trap domain of the extracellular Ca2+ -sensing receptor is required for L-amino acid sensing. J. Biol. Chem. 279 (50), 51739-51744. doi:10.1074/jbc.M406164/200 
Murray, R. G. (1986). The mammalian taste bud type III cell: a critical analysis. J Ultrastruct Mol Struct Res 95 (1-3), 175-188. doi:10.1016/0889-1605(86) 90039-x

Muto, T., Tsuchiya, D., Morikawa, K., and Jingami, H. (2007). Structures of the extracellular regions of the group II/III metabotropic glutamate receptors. Proc. Natl. Acad. Sci. U.S.A. 104 (10), 3759-3764. doi:10.1073/pnas.0611577104

Nakagita, T., Ishida, A., Matsuya, T., Kobayashi, T., Narukawa, M., Hirokawa, T., et al. (2019). Structural insights into the differences among lactisole derivatives in inhibitory mechanisms against the human sweet taste receptor. PLoS One 14 (3), e0213552. doi:10.1371/journal.pone.0213552

Narukawa, M., Toda, Y., Nakagita, T., Hayashi, Y., and Misaka, T. (2014). L-Theanine elicits umami taste via the T1R1 + T1R3 umami taste receptor. Amino Acids 46, 1583-1587. doi:10.1007/s00726-014-1713-3

Nelson, G., Chandrashekar, J., Hoon, M. A., Feng, L., Zhao, G., Ryba, N. J. P., et al. (2002). An amino-acid taste receptor. Nature 416, 199. doi:10.1038/nature726

Nelson, G., Hoon, M. A., Chandrashekar, J., Zhang, Y., Ryba, N. J. P., and Zuker, C. S. (2001). Mammalian sweet taste receptors. Cell 106 (3), 381-390. doi:10.1016/ S0092-8674(01)00451-2

Nemeth, E. F. (2013). Allosteric modulators of the extracellular calcium receptor. Drug Discov. Today Technol. 10 (2), e277-e284. doi:10.1016/j.ddtec.2012.11.002

Nemeth, E. F., Heaton, W. H., Miller, M., Fox, J., Balandrin, M. F., Van Wagenen, B. C., et al. (2004). Pharmacodynamics of the type II calcimimetic compound cinacalcet HCl. J. Pharmacol. Exp. Therapeut. 308, 627-635. doi:10.1124/jpet. 103.057273

Nemeth, E. F., Van Wagenen, B. C., and Balandrin, M. F. (2018). Discovery and development of calcimimetic and calcilytic compounds. Prog. Med. Chem. 57, 1-86. doi:10.1016/bs.pmch.2017.12.001

Nowak, S., Di Pizio, A., Levit, A., Niv, M. Y., Meyerhof, W., and Behrens, M. (2018). Reengineering the ligand sensitivity of the broadly tuned human bitter taste receptor TAS2R14. Biochim. Biophys. Acta Gen. Subj. 1862 (10), 2162-2173. doi:10.1016/j.bbagen.2018.07.009

Ohkuri, T., Yasumatsu, K., Horio, N., Jyotaki, M., Margolskee, R. F., and Ninomiya, Y. (2009). Multiple sweet receptors and transduction pathways revealed in knockout mice by temperature dependence and gurmarin sensitivity. Am. J. Physiol. Regul. Integr. Comp. Physiol. 296 (4), R960-R971. doi:10.1152/ ajpregu.91018.2008

Ohsu, T., Amino, Y., Nagasaki, H., Yamanaka, T., Takeshita, S., Hatanaka, T., et al. (2010). Involvement of the calcium-sensing receptor in human taste perception. J. Biol. Chem. 285 (2), 1016-1022. doi:10.1074/jbc.M109.029165

Pal Choudhuri, S., Delay, R. J., and Delay, E. R. (2016). Metabotropic glutamate receptors are involved in the detection of IMP and L-amino acids by mouse taste sensory cells. Neuroscience 316, 94-108. doi:10.1016/j.neuroscience.2015. 12.008

Park, J., Selvam, B., Sanematsu, K., Shigemura, N., Shukla, D., and Procko, E. (2019). Structural architecture of a dimeric class C GPCR based on cotrafficking of sweet taste receptor subunits. J. Biol. Chem. 294 (13), 4759-4774. doi:10.1074/jbc.RA118.006173

Perez, C. A., Huang, L., Rong, M., Kozak, J. A., Preuss, A. K., Zhang, H., et al. (2002). A transient receptor potential channel expressed in taste receptor cells. Nat. Neurosci. 5 (11), 1169-1176. doi:10.1038/nn952

Perez-Aguilar, J. M., Kang, S. G., Zhang, L., and Zhou, R. (2019). Modeling and structural characterization of the sweet taste receptor heterodimer. ACS Chem. Neurosci. 10 (11), 4579-4592. doi:10.1021/acschemneuro.9b00438

Petrel, C., Kessler, A., Dauban, P., Dodd, R. H., Rognan, D., and Ruat, M. (2004). Positive and negative allosteric modulators of the $\mathrm{Ca} 2+$-sensing receptor interact within overlapping but not identical binding sites in the transmembrane domain. J. Biol. Chem. 279 (18), 18990-18997. doi:10.1074/jbc.M400724200

Petrel, C., Kessler, A., Maslah, F., Dauban, P., Dodd, R. H., Rognan, D., et al. (2003). Modeling and mutagenesis of the binding site of Calhex 231, a novel negative allosteric modulator of the extracellular $\mathrm{Ca}(2+)$-sensing receptor. J. Biol. Chem. 278, 49487-49494. doi:10.1074/jbc.M308010200

Pidasheva, S., Grant, M., Canaff, L., Ercan, O., Kumar, U., and Hendy, G. N. (2006). Calcium-sensing receptor dimerizes in the endoplasmic reticulum: biochemical and biophysical characterization of CASR mutants retained intracellularly. Hum. Mol. Genet. 15 (14), 2200-2209. doi:10.1093/hmg/ddl145

Pin, J. P., Galvez, T., and Prézeau, L. (2003). Evolution, structure, and activation mechanism of family 3/C G-protein-coupled receptors. Pharmacol. Ther. 98 (3), 325-354. doi:10.1016/s0163-7258 z(03)00038-x
Pollak, M. R., Brown, E. M., Chou, Y. H., Hebert, S. C., Marx, S. J., Steinmann, B., et al. (1993). Mutations in the human $\mathrm{Ca}(2+)$-sensing receptor gene cause familial hypocalciuric hypercalcemia and neonatal severe hyperparathyroidism. Cell 75 (7), 1297-1303. doi:10.1016/0092-8674(93)90617-y

Pronin, A. N., Tang, H., Connor, J., and Keung, W. (2004). Identification of ligands for two human bitter T2R receptors. Chem. Senses 29 (7), 583-593. doi:10.1093/ chemse/bjh064

Pullicin, A. J., Penner, M. H., and Lim, J. (2017). Human taste detection of glucose oligomers with low degree of polymerization. PloS one 12 (8), e0183008. doi:10. 1371/journal.pone. 0183008

Pullicin, A. J., Penner, M. H., and Lim, J. (2019). The sweet taste of acarbose and maltotriose: relative detection and underlying mechanism. Chem. Senses 44, 123-128. doi:10.1093/chemse/bjy081

Pydi, S. P., Bhullar, R. P., and Chelikani, P. (2014a). Constitutive activity of bitter taste receptors (T2Rs). Adv. Pharmacol. 70, 303-326. doi:10.1016/B978-0-12417197-8.00010-9

Pydi, S. P., Jaggupilli, A., Nelson, K. M., Abrams, S. R., Bhullar, R. P., Loewen, M. C., et al. (2015). Abscisic acid acts as a blocker of the bitter taste G protein-coupled receptor T2R4. Biochemistry 54 (16), 2622-2631. doi:10.1021/acs.biochem. 5 b00265

Pydi, S. P., Singh, N., Upadhyaya, J., Bhullar, R. P., and Chelikani, P. (2014b). The third intracellular loop plays a critical role in bitter taste receptor activation. Biochim. Biophys. Acta 1838 (1 Pt B), 231-236. doi:10.1016/j.bbamem.2013.08.009

Pydi, S. P., Sobotkiewicz, T., Billakanti, R., Bhullar, R. P., Loewen, M. C., and Chelikani, P. (2014c). Amino acid derivatives as bitter taste receptor (T2R) blockers. J. Biol. Chem. 289 (36), 25054-25066. doi:10.1074/jbc.M114. 576975

Quinn, S. J., Ye, C. P., Diaz, R., Kifor, O., Bai, M., Vassilev, P., et al. (1997). The Ca2+-sensing receptor: a target for polyamines. Am. J. Physiol. 273, C1315-C1323. doi:10.1152/ajpcell.1997.273.4.C1315

Ray, K., Hauschild, B. C., Steinbach, P. J., Goldsmith, P. K., Hauache, O., and Spiegel, A. M. (1999). Identification of the cysteine residues in the aminoterminal extracellular domain of the human $\mathrm{Ca}(2+)$ receptor critical for dimerization. Implications for function of monomeric $\mathrm{Ca}(2+)$ receptor. J. Biol. Chem. 274 (39), 27642-27650. doi:10.1074/jbc.274.39.27642

Reed, D. R., Li, S., Li, X., Huang, L., Tordoff, M. G., Starling-Roney, R., et al. (2004). Polymorphisms in the taste receptor gene (Tas1r3) region are associated with saccharin preference in 30 mouse strains. J. Neurosci. 24 (4), 938-946. doi:10. 1523/jneurosci.1374-03.2004

Rifkin, B., and Bartoshuk, L. M. (1980). Taste synergism between monosodium glutamate and disodium 5'-guanylate. Physiol. Behav. 24 (6), 1169-1172. doi:10. 1016/0031-9384(80)90066-9

Rodgers, S., Glen, R. C., and Bender, A. (2006). Characterizing bitterness: identification of key structural features and development of a classification model. J. Chem. Inf. Model. 46, 569-576. doi:10.1021/ci0504418

Roebber, J. K., Roper, S. D., and Chaudhari, N. (2019). The role of the anion in salt $(\mathrm{NaCl})$ detection by mouse taste buds. J. Neurosci. 39, 6224-6232. doi:10.1523/ JNEUROSCI.2367-18.2019

Roland, W. S., Gouka, R. J., Gruppen, H., Driesse, M., van Buren, L., Smit, G., et al. (2014). 6-methoxyflavanones as bitter taste receptor blockers for hTAS2R39. PLoS One 9, e94451. doi:10.1371/journal.pone.0094451

Roland, W. S., van Buren, L., Gruppen, H., Driesse, M., Gouka, R. J., Smit, G., et al. (2013). Bitter taste receptor activation by flavonoids and isoflavonoids: modeled structural requirements for activation of hTAS2R14 and hTAS2R39. J. Agric. Food Chem. 61, 10454-10466. doi:10.1021/jf403387p

Roland, W. S., Vincken, J. P., Gouka, R. J., van Buren, L., Gruppen, H., and Smit, G. (2011). Soy isoflavones and other isoflavonoids activate the human bitter taste receptors hTAS2R14 and hTAS2R39. J. Agric. Food Chem. 59, 11764-11771. doi:10.1021/jf202816u

Roper, S. D. (2007). Signal transduction and information processing in mammalian taste buds. Pflügers Archiv 454 (5), 759-776. doi:10.1007/s00424-007-0247-x

Rosenbaum, D. M., Rasmussen, S. G. F., and Kobilka, B. K. (2009). The structure and function of G-protein-coupled receptors. Nature 459 (7245), 356-363. doi:10.1038/nature 08144

Ruiz-Avila, L., Wong, G. T., Damak, S., and Margolskee, R. F. (2001). Dominant loss of responsiveness to sweet and bitter compounds caused by a single mutation in alpha -gustducin. Proc. Natl. Acad. Sci. U.S.A. 98 (15), 8868-8873. doi:10.1073/pnas.151235798 
Sakurai, T., Misaka, T., Ishiguro, M., Masuda, K., Sugawara, T., Ito, K., et al. (2010a). Characterization of the beta-D-glucopyranoside binding site of the human bitter taste receptor hTAS2R16. J. Biol. Chem. 285 (36), 28373-28378. doi:10.1074/jbc.M110.144444

Sakurai, T., Misaka, T., Ueno, Y., Ishiguro, M., Matsuo, S., Ishimaru, Y., et al. (2010b). The human bitter taste receptor, hTAS2R16, discriminates slight differences in the configuration of disaccharides. Biochem. Biophys. Res. Commun. 402 (4), 595-601. doi:10.1016/j.bbrc.2010.10.059

San Gabriel, A., Uneyama, H., Maekawa, T., and Torii, K. (2009). The calciumsensing receptor in taste tissue. Biochem. Biophys. Res. Commun. 378 (3), 414-418. doi:10.1016/j.bbrc.2008.11.060

Sandal, M., Behrens, M., Brockhoff, A., Musiani, F., Giorgetti, A., Carloni, P., et al. (2015). Evidence for a transient additional ligand binding site in the TAS2R46 bitter taste receptor. J. Chem. Theor. Comput. 11 (9), 4439-4449. doi:10.1021/ acs.jctc.5b00472

Sanematsu, K., Kusakabe, Y., Shigemura, N., Hirokawa, T., Nakamura, S., Imoto, T., et al. (2014). Molecular mechanisms for sweet-suppressing effect of gymnemic acids. J. Biol. Chem. 289, 25711-25720. doi:10.1074/jbc.M114. 560409

Schiffman, S. S., Zervakis, J., Westall, H. L., Graham, B. G., Metz, A., Bennett, J. L., et al. (2000). Effect of antimicrobial and anti-inflammatory medications on the sense of taste. Physiol. Behav. 69, 413-424. doi:10.1016/s0031-9384(99)00262-0

Schoneberg, T., Schulz, A., Biebermann, H., Hermsdorf, T., Rompler, H., and Sangkuhl, K. (2004). Mutant G-protein-coupled receptors as a cause of human diseases. Pharmacol. Ther. 104 (3), 173-206. doi:10.1016/j.pharmthera.2004.08.008

Seifert, R., and Wenzel-Seifert, K. (2002). Constitutive activity of G-proteincoupled receptors: cause of disease and common property of wild-type receptors. Naunyn-Schmiedebergs Arch. Pharmacol. 366 (5), 381-416. doi:10. 1007/s00210-002-0588-0

Servant, G., Tachdjian, C., Tang, X. Q., Werner, S., Zhang, F., Li, X., et al. (2010). Positive allosteric modulators of the human sweet taste receptor enhance sweet taste. Proc. Natl. Acad. Sci. U.S.A. 107 (10), 4746-4751. doi:10.1073/pnas. 0911670107

Shaik, F. A., Jaggupilli, A., and Chelikani, P. (2019). Highly conserved intracellular H208 residue influences agonist selectivity in bitter taste receptor T2R14. Biochimica et biophysica acta. Biomembranes 1861 (12), 183057. doi:10. 1016/j.bbamem.2019.183057

Shi, P., and Zhang, J. (2009). Extraordinary diversity of chemosensory receptor gene repertoires among vertebrates. Results Probl. Cell Differ. 47, 1-23. doi:10. 1007/400_2008_4

Shim, J., Son, H. J., Kim, Y., Kim, K. H., Kim, J. T., Moon, H., et al. (2015). Modulation of sweet taste by umami compounds via sweet taste receptor subunit hT1R2. PLoS One 10 (4), e0124030. doi:10.1371/journal.pone. 0124030

Shimizu, M., Goto, M., Kawai, T., Yamashita, A., and Kusakabe, Y. (2014). Distinct human and mouse membrane trafficking systems for sweet taste receptors T1r2 and T1r3. PLoS One 9 (7), e100425. doi:10.1371/journal.pone.0100425

Silve, C., Petrel, C., Leroy, C., Bruel, H., Mallet, E., Rognan, D., et al. (2005). Delineating a $\mathrm{Ca} 2+$ binding pocket within the venus flytrap module of the human calcium-sensing receptor. J. Biol. Chem. 280 (45), 37917-37923. doi:10. 1074/jbc.M506263200

Singh, N., Pydi, S. P., Upadhyaya, J., and Chelikani, P. (2011). Structural basis of activation of bitter taste receptor T2R1 and comparison with Class A G-proteincoupled receptors (GPCRs). J. Biol. Chem. 286 (41), 36032-36041. doi:10.1074/ jbc.M111.246983

Slack, J. P., Brockhoff, A., Batram, C., Menzel, S., Sonnabend, C., Born, S., et al. (2010). Modulation of bitter taste perception by a small molecule hTAS2R antagonist. Curr. Biol. 20 (12), 1104-1109. doi:10.1016/j.cub.2010.04.043

Soares, S., Kohl, S., Thalmann, S., Mateus, N., Meyerhof, W., and De Freitas, V. (2013). Different phenolic compounds activate distinct human bitter taste receptors. J. Agric. Food Chem. 61, 1525-1533. doi:10.1021/jf304198k

Soares, S., Silva, M. S., García-Estevez, I., Grobmann, P., Brás, N., Brandão, E., et al. (2018). Human bitter taste receptors are activated by different classes of polyphenols. J. Agric. Food Chem. 66, 8814-8823. doi:10.1021/acs.jafc.8b03569

Sonntag, T., Kunert, C., Dunkel, A., and Hofmann, T. (2010). Sensory-guided identification of N-(1-methyl-4-oxoimidazolidin-2-ylidene)-alpha-amino acids as contributors to the thick-sour and mouth-drying orosensation of stewed beef juice. J. Agric. Food Chem. 58, 6341-6350. doi:10.1021/jf100591c
Suess, B., Brockhoff, A., Meyerhof, W., and Hofmann, T. (2018). The odorant (R)Citronellal attenuates caffeine bitterness by inhibiting the bitter receptors TAS2R43 and TAS2R46. J. Agric. Food Chem. 66, 2301-2311. doi:10.1021/ acs.jafc.6b03554

Sugita, M. (2006). Taste perception and coding in the periphery. Cell. Mol. Life Sci. 63 (17), 2000-2015. doi:10.1007/s00018-006-6100-0

Sullivan, J. M., Borecki, A. A., and Oleskevich, S. (2010). Stem and progenitor cell compartments within adult mouse taste buds. Eur. J. Neurosci. 31 (9), 1549-1560. doi:10.1111/j.1460-9568.2010.07184.x

Talmon, M., Rossi, S., Lim, D., Pollastro, F., Palattella, G., Ruffinatti, F. A., et al. (2019). Absinthin, an agonist of the bitter taste receptor hTAS2R46, uncovers an ER-to-mitochondria $\mathrm{Ca}^{2+}$-shuttling event. J. Biol. Chem. 294, 12472-12482. doi:10.1074/jbc.RA119.007763

Tan, J., Abrol, R., Trzaskowski, B., and Goddard, W. A., 3rd (2012). 3D structure prediction of TAS2R38 bitter receptors bound to agonists phenylthiocarbamide (PTC) and 6-n-propylthiouracil (PROP). J. Chem. Inf. Model. 52 (7), 1875-1885. doi:10.1021/ci300133a

Taruno, A., Vingtdeux, V., Ohmoto, M., Ma, Z., Dvoryanchikov, G., Li, A., et al. (2013). CALHM1 ion channel mediates purinergic neurotransmission of sweet, bitter and umami tastes. Nature 495 (7440), 223-226. doi:10.1038/ nature 11906

Temussi, P. A. (2009). Sweet, bitter and umami receptors: a complex relationship. Trends Biochem. Sci. 34 (6), 296-302. doi:10.1016/j.tibs.2009.02.005

Thomas, A., Sulli, C., Davidson, E., Berdougo, E., Phillips, M., Puffer, B. A., et al. (2017). The bitter taste receptor TAS2R16 achieves high specificity and accommodates diverse glycoside ligands by using a two-faced binding pocket. Sci. Rep. 7 (1), 7753. doi:10.1038/s41598-017-07256-y

Tinti, J. M., and Nofre, C., and (1991). "Design of sweeteners: A rational approach," in Sweeteners: discovery, molecular design, and chemoreception. Editors D. E. Walters, F.T. Orthoefer, and G. E. DuBois (American Chemical Society: Washington, DC), 88-99.

Toda, Y., Nakagita, T., Hayakawa, T., Okada, S., Narukawa, M., Imai, H., et al. (2013). Two distinct determinants of ligand specificity in T1R1/T1R3 (the umami taste receptor). J. Biol. Chem. 288, 36863-36877. doi:10.1074/jbc.M113. 494443

Toda, Y., Nakagita, T., Hirokawa, T., Yamashita, Y., Nakajima, A., Narukawa, M., et al. (2018). Positive/negative allosteric modulation switching in an umami taste receptor (T1R1/T1R3) by a natural flavor compound, methional. Sci. Rep. 8 (1), 11796. doi:10.1038/s41598-018-30315-x

Tonosaki, K., and Funakoshi, M. (1988). Cyclic nucleotides may mediate taste transduction. Nature 331 (6154), 354-356. doi:10.1038/331354a0

Tsuchiya, D., Kunishima, N., Kamiya, N., Jingami, H., and Morikawa, K. (2002). Structural views of the ligand-binding cores of a metabotropic glutamate receptor complexed with an antagonist and both glutamate and Gd3+. Proc. Natl. Acad. Sci. U.S.A. 99 (5), 2660-2665. doi:10.1073/pnas.052708599

Tu, Y. z J., Teng, B., Chang, R. B., Artiga, D. J., Turner, H. N., et al. (2018). An evolutionarily conserved gene family encodes proton-selective ion channels. Science 359, 1047-1050. doi:10.1126/science.aao3264

Uchida, Y., and Sato, T. (1997). Intracellular calcium increase in gerbil taste cell by amino acid sweeteners. Chem. Senses 22 (1), 83-91. doi:10.1093/chemse/22.1.83

Ueda, T., Yonemitsu, M., Tsubuku, T., Sakaguchi, M., and Miyajima, R. (1997). Flavor characteristics of glutathione in raw and cooked foodstuffs. Biosci. Biotechnol. Biochem. 61, 1977-1980.

Ueda, Y., Sakaguchi, M., Hirayama, K., Miyajima, R., and Kimizuka, A. (1990). Characteristic flavor constituents in water extract of garlic. Agric. Biol. Chem. 54, 163-169. doi:10.1080/00021369.1990.10869909

Ueno, Y., Sakurai, T., Okada, S., Abe, K., and Misaka, T. (2011). Human bitter taste receptors hTAS2R8 and hTAS2R39 with differential functions to recognize bitter peptides. Biosci. Biotechnol. Biochem. 75, 1188-1190. doi:10.1271/bbb.100893

Upadhyaya, J., Pydi, S. P., Singh, N., Aluko, R. E., and Chelikani, P. (2010). Bitter taste receptor T2R1 is activated by dipeptides and tripeptides. Biochem. Biophys. Res. Commun. 398, 331-335. doi:10.1016/j.bbrc.2010.06.097

Upadhyaya, J., Singh, N., Bhullar, R. P., and Chelikani, P. (2015). The structurefunction role of C-terminus in human bitter taste receptor T2R4 signaling. Biochim. Biophys. Acta 1848 (7), 1502-1508. doi:10.1016/j.bbamem.2015.03.035

Urwyler, S. (2011). Allosteric modulation of family C G-protein-coupled receptors: from molecular insights to therapeutic perspectives. Pharmacol. Rev. 63 (1), 59-126. doi:10.1124/pr.109.002501 
Vandenbeuch, A., Anderson, C. B., Parnes, J., Enjyoji, K., Robson, S. C., Finger, T. E., et al. (2013). Role of the ectonucleotidase NTPDase2 in taste bud function. Proc. Natl. Acad. Sci. U.S.A. 110, 14789-14794. doi:10.1073/pnas.1309468110

Vandenbeuch, A., Clapp, T. R., and Kinnamon, S. C. (2008). Amiloride-sensitive channels in type I fungiform taste cells in mouse. BMC Neurosci. 9, 1. doi:10. 1186/1471-2202-9-1

Venkatakrishnan, A. J., Deupi, X., Lebon, G., Tate, C. G., Schertler, G. F., and Babu, M. M. (2013). Molecular signatures of G-protein-coupled receptors. Nature 494, 185. doi:10.1038/nature11896

Verbeurgt, C., Veithen, A., Carlot, S., Tarabichi, M., Dumont, J. E., Hassid, S., et al. (2017). The human bitter taste receptor T2R 38 is broadly tuned for bacterial compounds. PLoS One 12, e0181302. doi:10.1371/journal.pone.0181302

Wang, M., Yao, Y., Kuang, D., and Hampson, D. R. (2006). Activation of family C G-protein-coupled receptors by the tripeptide glutathione. J. Biol. Chem. 281 (13), 8864-8870. doi:10.1074/jbc.M512865200

Wang, Y., Zajac, A. L., Lei, W., Christensen, C. M., Margolskee, R. F., Bouysset, C., et al. (2019). Metal ions activate the human taste receptor TAS2R7. Chem. Senses 44 (5), 339-347. doi:10.1093/chemse/bjz024

Ward, D. T. (2004). Calcium receptor-mediated intracellular signalling. Cell Calcium 35 (3), 217-228. doi:10.1016/j.ceca.2003.10.017

Ward, D. T., Brown, E. M., and Harris, H. W. (1998). Disulfide bonds in the extracellular calcium-polyvalent cation-sensing receptor correlate with dimer formation and its response to divalent cations in vitro. J. Biol. Chem. 273 (23), 14476-14483. doi:10.1074/jbc.273.23.14476

Wettschureck, N., Lee, E., Libutti, S. K., Offermanns, S., Robey, P. G., and Spiegel, A. M. (2007). Parathyroid-specific double knockout of gq and G11 $\alpha$-subunits leads to a phenotype resembling germline knockout of the extracellular Ca2+sensing receptor. Mol. Endocrinol. 21 (1), 274-280. doi:10.1210/me.20060110

White, J. H., Wise, A., Main, M. J., Green, A., Fraser, N. J., Disney, G. H., et al. (1998). Heterodimerization is required for the formation of a functional GABA(B) receptor. Nature 396 (6712), 679-682. doi:10.1038/25354

Widler, L. (2011). Calcilytics: antagonists of the calcium-sensing receptor for the treatment of osteoporosis. Future Med. Chem. 3 (5), 535-547. doi:10.4155/fmc. 11.17

Winnig, M., Bufe, B., Kratochwil, N. A., Slack, J. P., and Meyerhof, W. (2007). The binding site for neohesperidin dihydrochalcone at the human sweet taste receptor. BMC Struct. Biol. 7, 66. doi:10.1186/1472-6807-7-66

Winnig, M., Bufe, B., and Meyerhof, W. (2005). Valine 738 and lysine 735 in the fifth transmembrane domain of rTas1r3 mediate insensitivity towards lactisole of the rat sweet taste receptor. BMC Neurosci. 6, 22. doi:10.1186/1471-2202-6-22

Wong, G. T., Gannon, K. S., and Margolskee, R. F. (1996). Transduction of bitter and sweet taste by gustducin. Nature 381 (6585), 796-800. doi:10.1038/ $381796 \mathrm{a} 0$

Xu, H., Staszewski, L., Tang, H., Adler, E., Zoller, M., and Li, X. (2004). Different functional roles of T1R subunits in the heteromeric taste receptors. Proc. Natl. Acad. Sci. U.S.A. 101 (39), 14258-14263. doi:10.1073/pnas.0404384101

Xu, Q., Singh, N., Hong, H., Yan, X., Yu, W., Jiang, X., et al. (2019). Hen proteinderived peptides as the blockers of human bitter taste receptors T2R4, T2R7 and T2R14. Food Chem. 283, 621-627. doi:10.1016/j.foodchem.2019.01.059

Yamada, K., Nakazawa, M., Matsumoto, K., Tagami, U., Hirokawa, T., Homma, K., et al. (2019). Unnatural tripeptides as potent positive allosteric modulators of T1R2/T1R3. ACS Med. Chem. Lett. 10 (5), 800-805. doi:10.1021/ acsmedchemlett.9b00051

Yamamoto, M., Terada, Y., Motoyama, T., Saito, T., and Ito, K. (2020). Sweet proteins lysozyme and thaumatin are protein-type agonists for the calciumsensing receptor. Biochem. Biophys. Res. Commun. 521, 227-231. doi:10.1016/j. bbrc.2019.10.111

Yang, J., Bai, W., Zeng, X., and Cui, C. (2019). $\gamma$-[Glu](n=1,2)-Phe/-Met/-Val stimulates gastrointestinal hormone (CCK and GLP-1) secretion by activating the calcium-sensing receptor. Food Funct. 10, 4071-4080. doi:10.1039/C9FO00313D.

Ye, C., Ho-Pao, C. L., Kanazirska, M., Quinn, S., Rogers, K., Seidman, C. E., et al. (1997). Amyloid-beta proteins activate $\mathrm{Ca}(2+)$-permeable channels through calcium-sensing receptors. J. Neurosci. Res. 47, 547-554. doi:10.1002/(sici) 1097-4547(19970301)47:5<547::aid-jnr10>3.0.co;2-v

Yoshida, R., Miyauchi, A., Yasuo, T., Jyotaki, M., Murata, Y., Yasumatsu, K., et al. (2009). Discrimination of taste qualities among mouse fungiform taste bud cells. J Physiol 587 (Pt 18), 4425-4439. doi:10.1113/jphysiol.2009.175075

Yoshida, R., Sanematsu, K., Shigemura, N., Yasumatsu, K., and Ninomiya, Y. (2005). Taste receptor cells responding with action potentials to taste stimuli and their molecular expression of taste related genes. Chem. Senses 30 (Suppl. 1), i19-i20. doi:10.1093/chemse/bjh092

Yoshida, R., Shigemura, N., Sanematsu, K., Yasumatsu, K., Ishizuka, S., and Ninomiya, Y. (2006). Taste responsiveness of fungiform taste cells with action potentials. J. Neurophysiol. 96 (6), 3088-3095. doi:10.1152/jn.00409.2006

Yoshida, R., Takai, S., Sanematsu, K., Margolskee, R. F., Shigemura, N., and Ninomiya, Y. (2018). Bitter taste responses of gustducin-positive taste cells in mouse fungiform and circumvallate papillae. Neuroscience 369, 29-39. doi:10.1016/j.neuroscience.2017.10.047

Zhang, C., Alashi, A. M., Singh, N., Liu, K., Chelikani, P., and Aluko, R. E. (2018). Beef protein-derived peptides as bitter taste receptor T2R4 blockers. J. Agric. Food Chem. 66 (19), 4902-4912. doi:10.1021/acs.jafc.8b00830

Zhang, C., Huang, Y., Jiang, Y., Mulpuri, N., Wei, L., Hamelberg, D., et al. (2014). Identification of an L-phenylalanine binding site enhancing the cooperative responses of the calcium-sensing receptor to calcium. J. Biol. Chem. 289 (8), 5296-5309. doi:10.1074/jbc.M113.537357

Zhang, F., Klebansky, B., Fine, R. M., Liu, H., Xu, H., Servant, G., et al. (2010). Molecular mechanism of the sweet taste enhancers. Proc. Natl. Acad. Sci. U.S.A. 107 (10), 4752-4757. doi:10.1073/pnas.0911660107

Zhang, F., Klebansky, B., Fine, R. M., Xu, H., Pronin, A., Liu, H., et al. (2008). Molecular mechanism for the umami taste synergism. Proc. Natl. Acad. Sci. U.S.A. 105, 20930-20934. doi:10.1073/pnas.0810174106

Zhang, J., Jin, H., Zhang, W., Ding, C., O'Keeffe, S., Ye, M., et al. (2019). Sour sensing from the tongue to the brain. Cell 179, 392-402.e15. doi:10.1016/j.cell. 2019.08.031

Zhang, Y., Hoon, M. A., Chandrashekar, J., Mueller, K. L., Cook, B., Wu, D., et al. (2003). Coding of sweet, bitter, and umami tastes: different receptor cells sharing similar signaling pathways. Cell 112 (3), 293-301. doi:10.1016/S00928674(03)00071-0

Zhang, Y., Wang, X., Li, X., Peng, S., Wang, S., Huang, C. Z., et al. (2017). Identification of a specific agonist of human TAS2R14 from Radix Bupleuri through virtual screening, functional evaluation and binding studies. Sci. Rep. 7 (1), 12174. doi:10.1038/s41598-017-11720-0

Zhang, Z., Qiu, W., Quinn, S. J., Conigrave, A. D., Brown, E. M., and Bai, M. (2002). Three adjacent serines in the extracellular domains of the $\mathrm{CaR}$ are required for L-amino acid-mediated potentiation of receptor function. J. Biol. Chem. 277 (37), 33727-33735. doi:10.1074/jbc.M200976200

Zhao, G. Q., Zhang, Y., Hoon, M. A., Chandrashekar, J., Erlenbach, I., Ryba, N. J. P., et al. (2003). The receptors for mammalian sweet and umami taste. Cell 115 (3), 255-266. doi:10.1016/S0092-8674(03)00844-4

Zhao, M., Xu, X. Q., Meng, X. Y., and Liu, B. (2018). The heptahelical domain of the sweet taste receptor T1R2 is a new allosteric binding site for the sweet taste modulator amiloride that modulates sweet taste in a speciesdependent manner. J. Mol. Neurosci. 66 (2), 207-213. doi:10.1007/ s12031-018-1156-5

Conflict of Interest: The authors declare that the research was conducted in the absence of any commercial or financial relationships that could be construed as a potential conflict of interest.

Copyright (๑) 2020 Ahmad and Dalziel. This is an open-access article distributed under the terms of the Creative Commons Attribution License (CC BY). The use, distribution or reproduction in other forums is permitted, provided the original author(s) and the copyright owner(s) are credited and that the original publication in this journal is cited, in accordance with accepted academic practice. No use, distribution or reproduction is permitted which does not comply with these terms. 